Misc. Records

XI. Lau.

\title{
BERNICE P. BISHOP MUSEUM
} HONOLULU, HAWAII

\section{FIELD NOTE BOOK}


BERNICE P. BISHOP MUSEUM

HONOLULU, HAWAII

Field Note Book

Subject

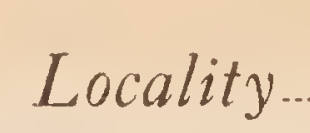

Member of Staff 


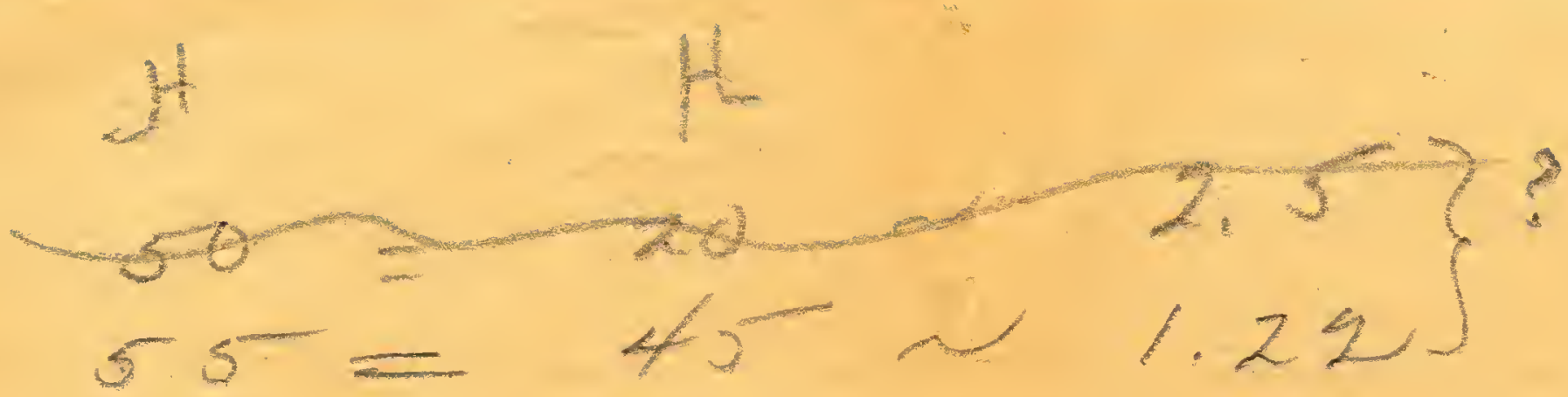

$$
\begin{aligned}
& 70=60 \propto 1.16
\end{aligned}
$$

$\left.\begin{array}{l}290=210 \sim 1.38 \\ 315=205 \times 1.5 .3 .\end{array}\right\}$

[are nading ofter accilut were malfiginel by $1.29+1 \mathrm{~km}$ $330-290 \alpha+1.3\}$ af remanang adyubat for $370=295 \sim 1.25$. sea lurel

$$
\begin{aligned}
& 445=355 \sim 1.25 \\
& 470=3751 \sim 7.25 \\
& 515=405 \sim \frac{1.27}{15.48}
\end{aligned}
$$




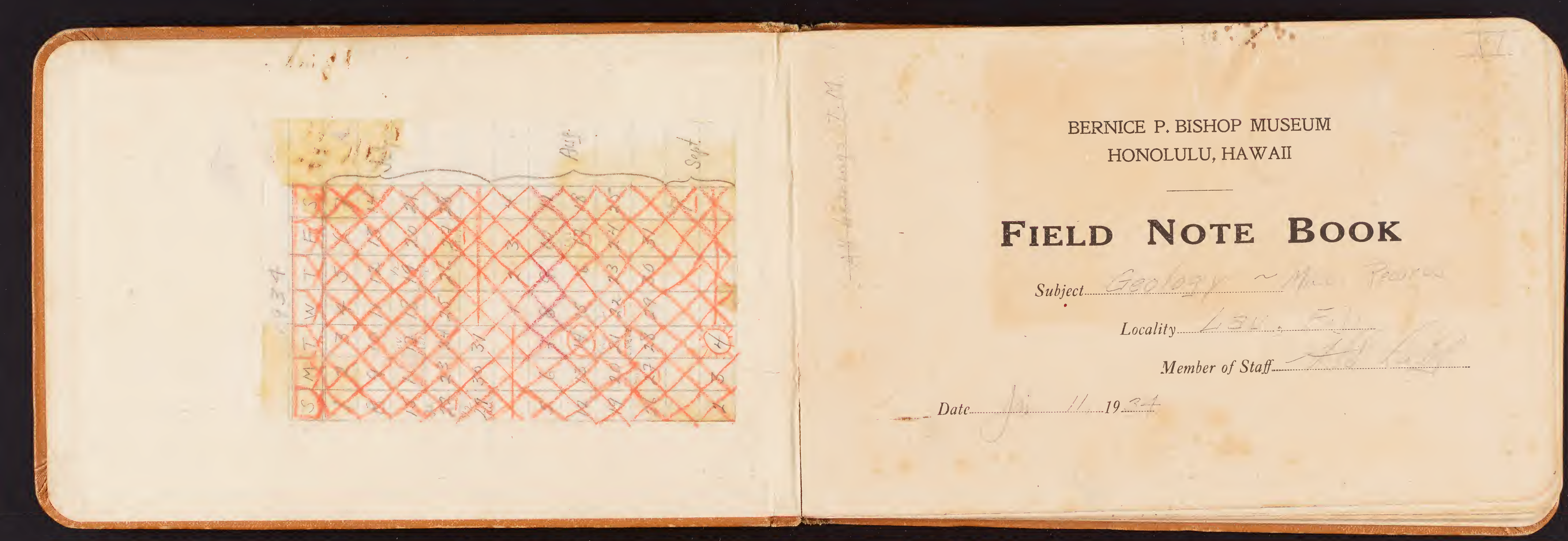




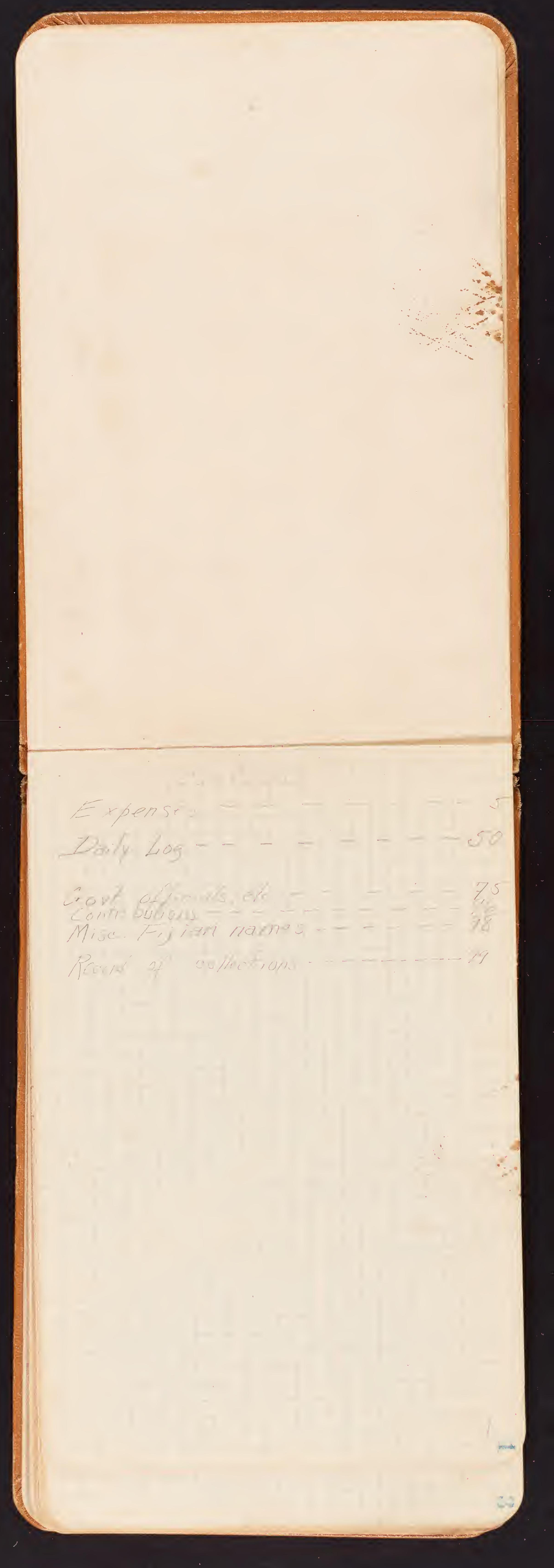




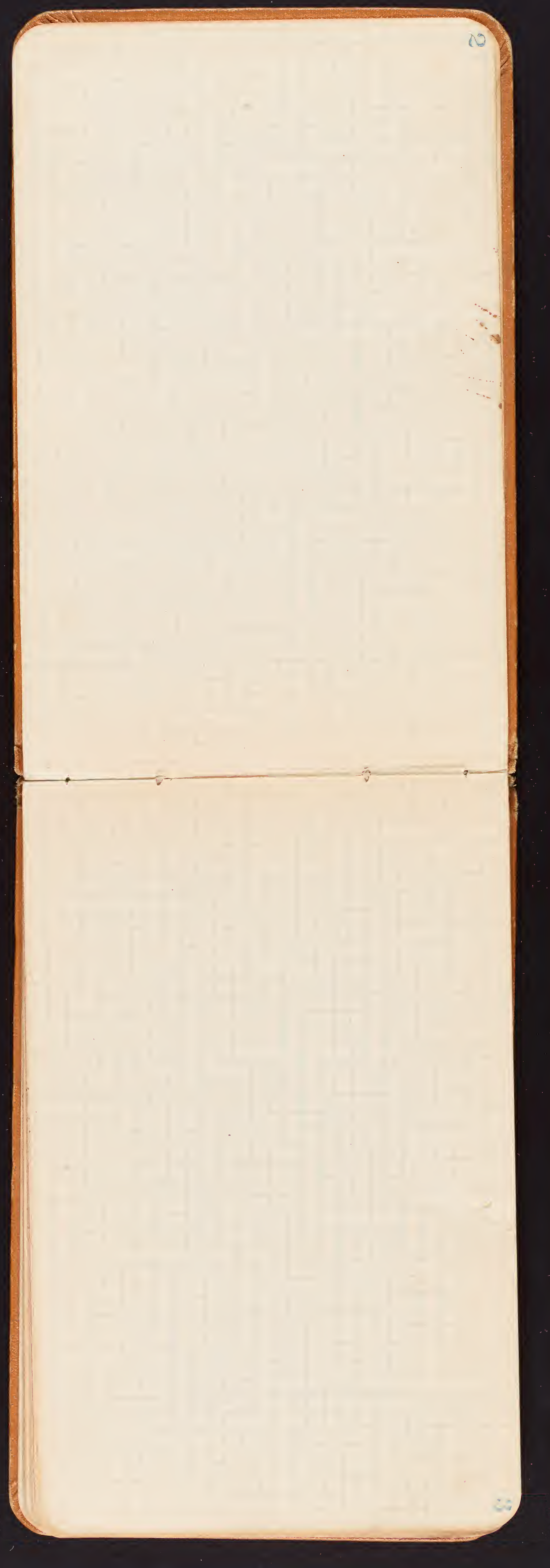




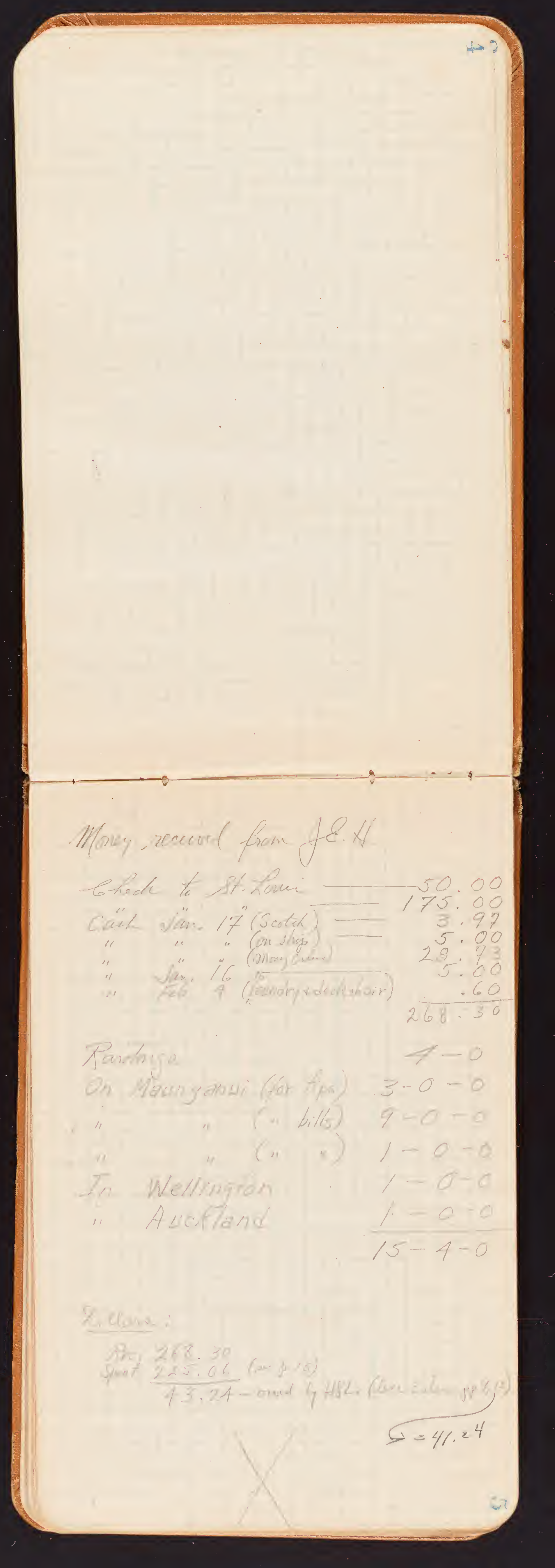




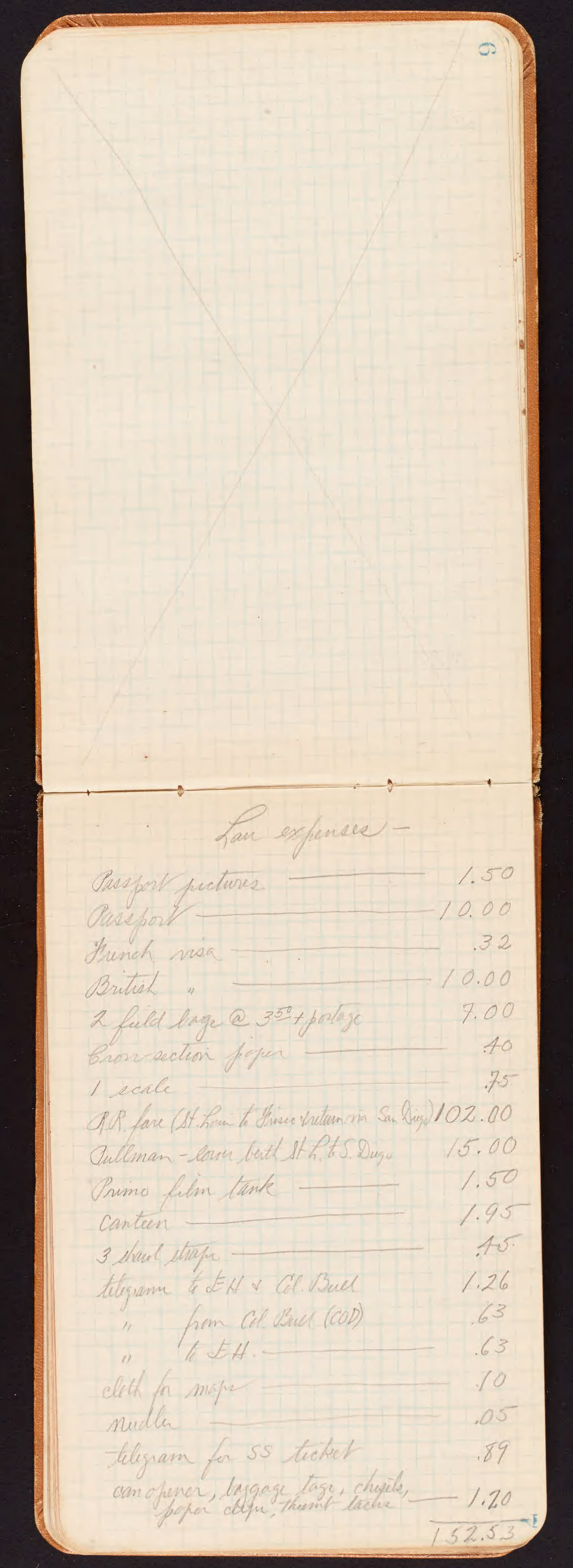




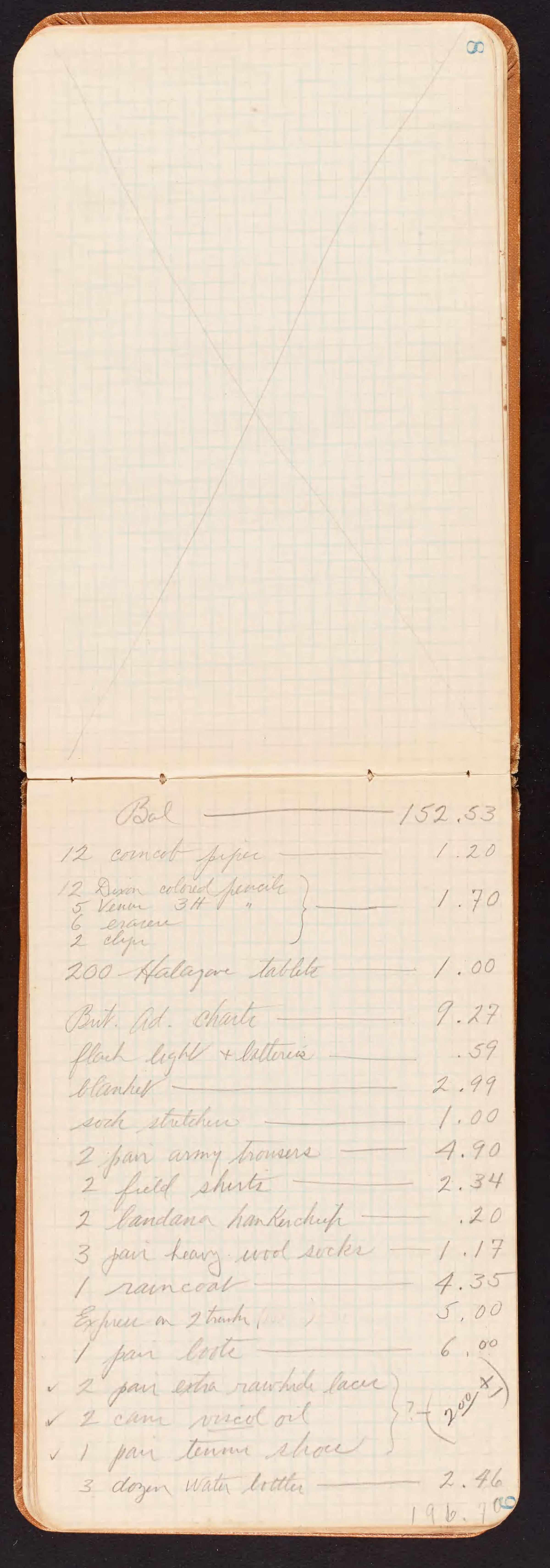




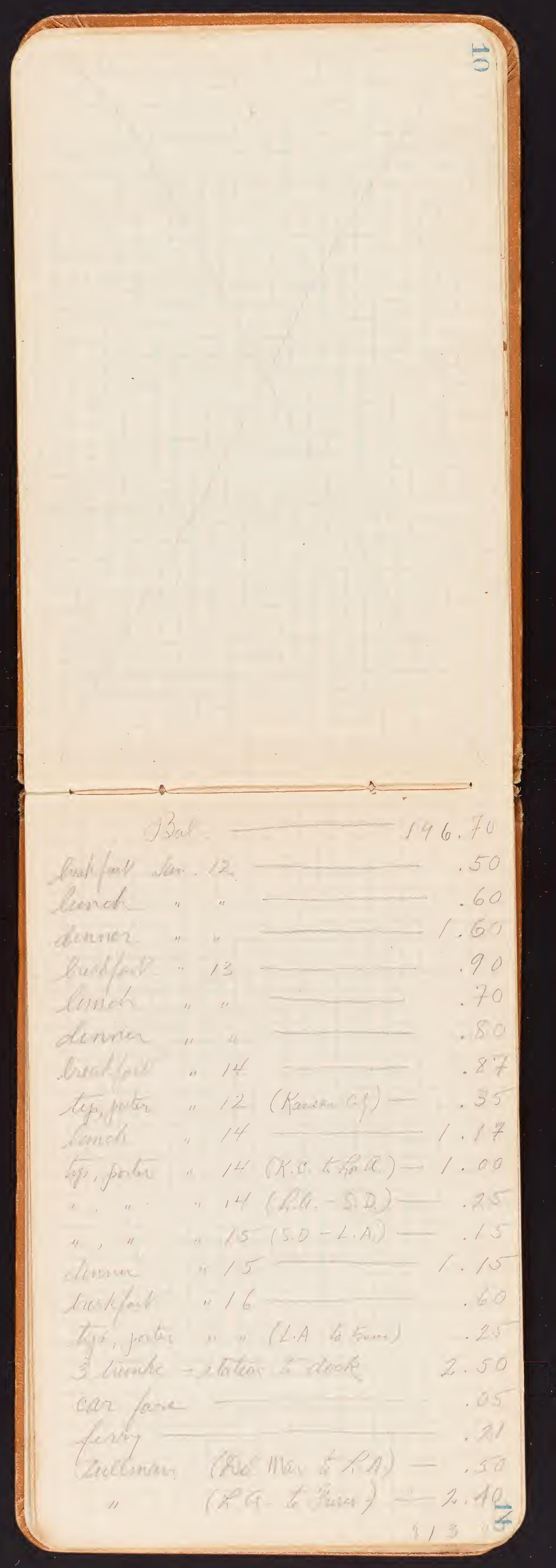




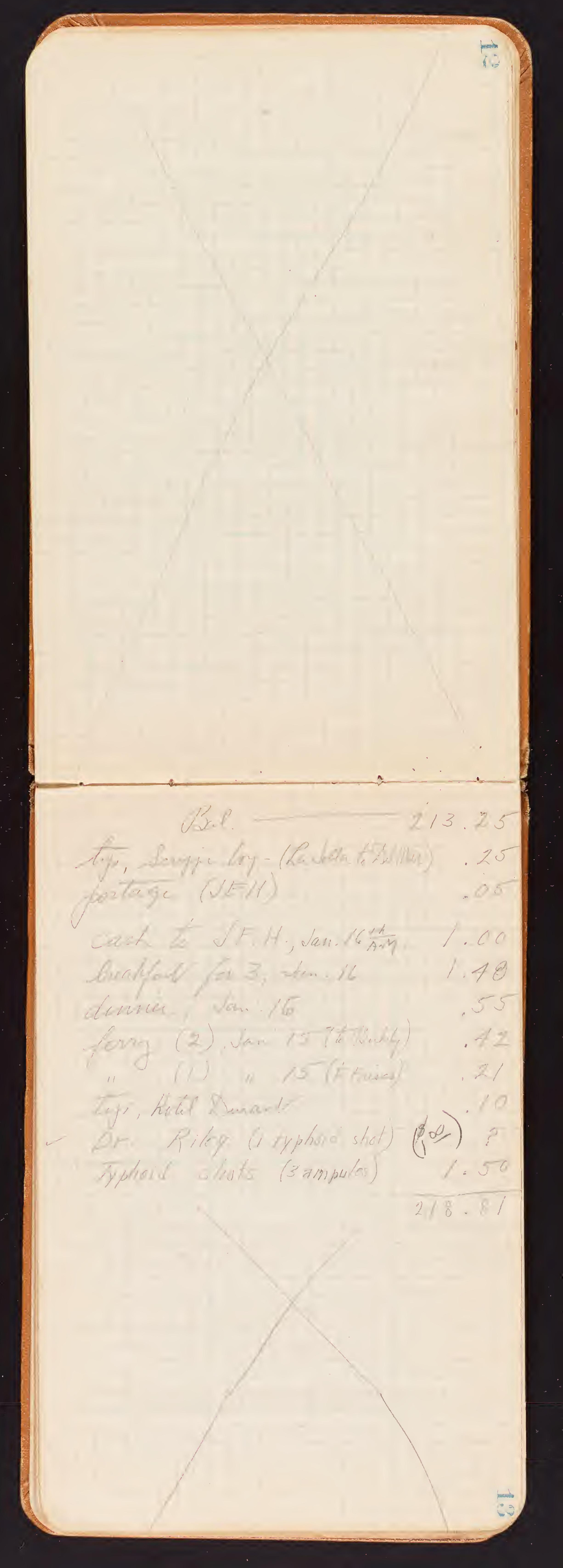




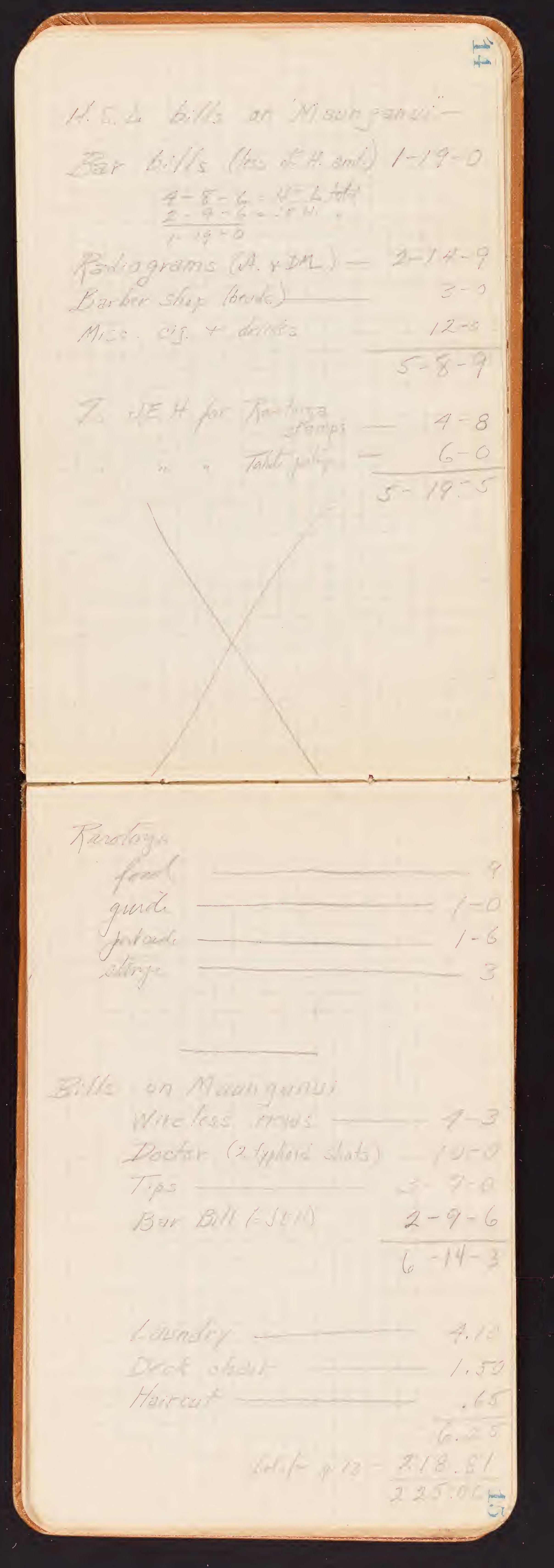




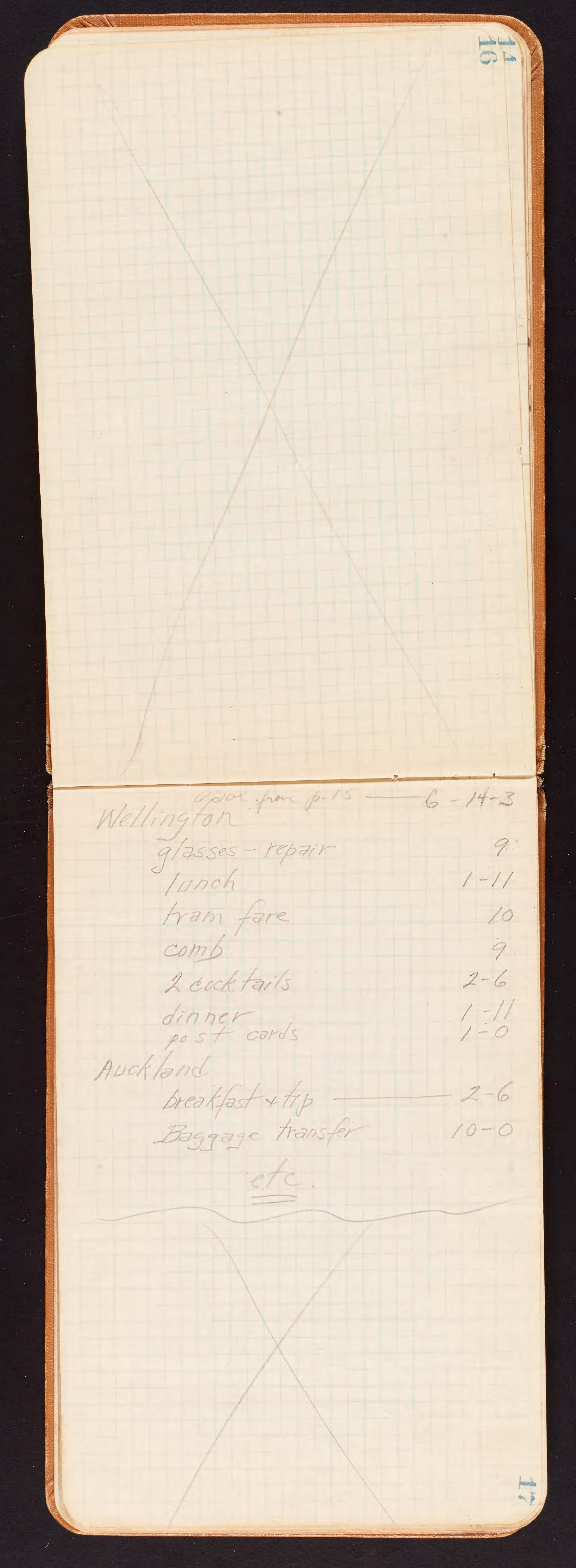




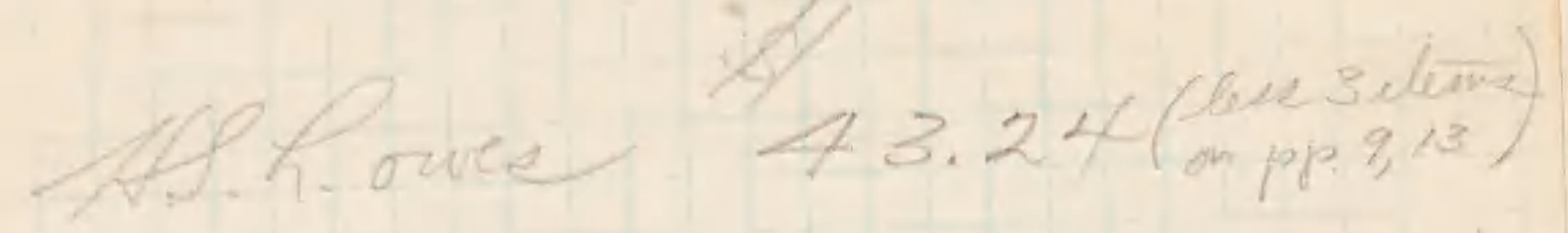

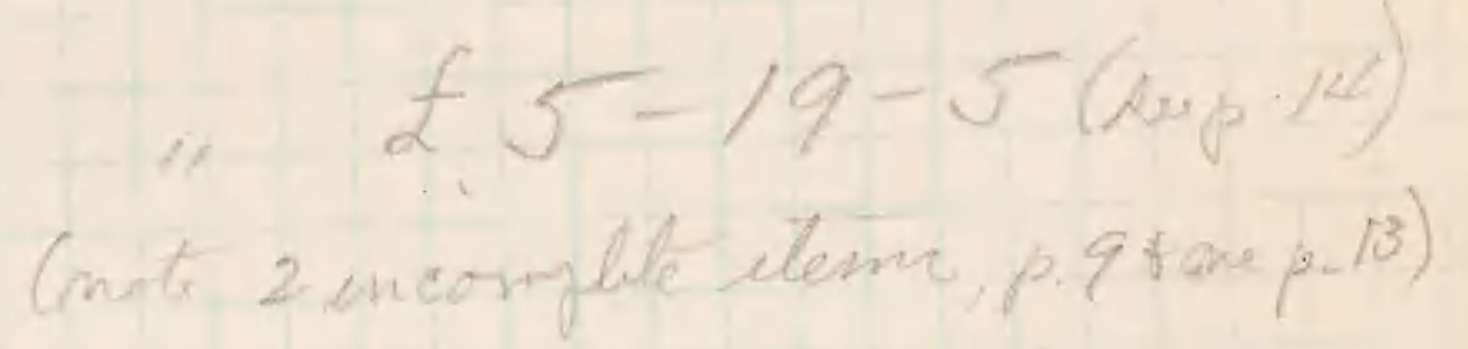

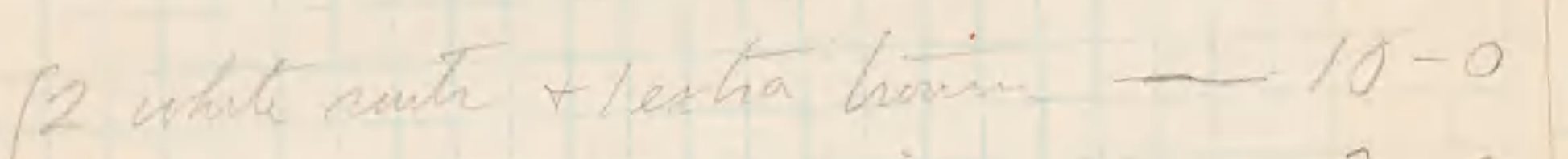
duntur $\quad 2-0$

asaullh $3-0$

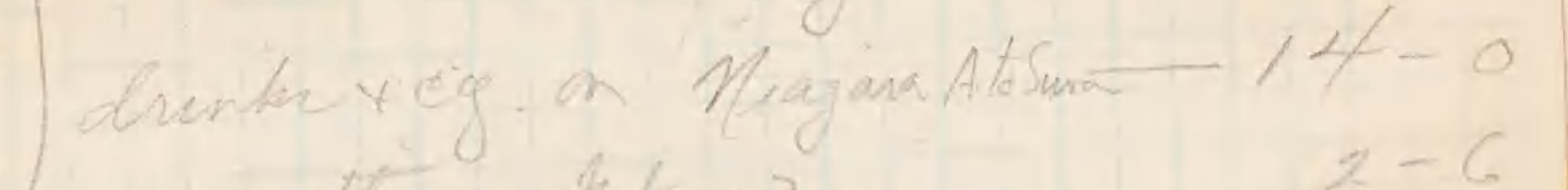

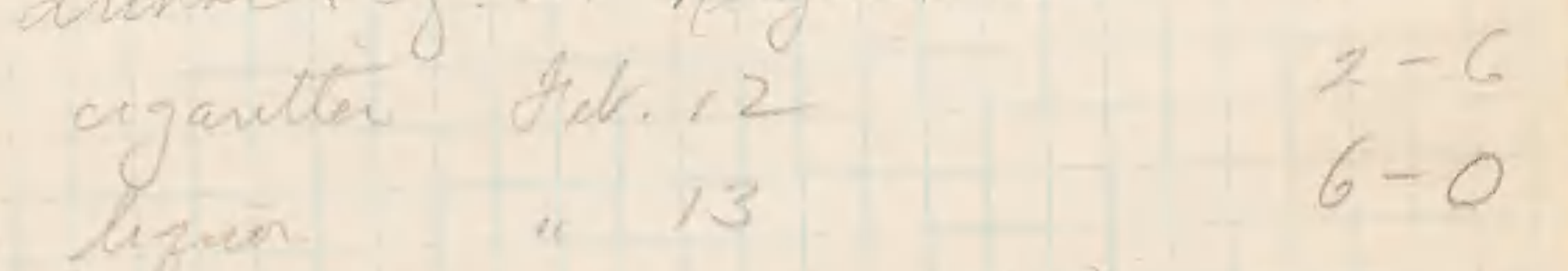

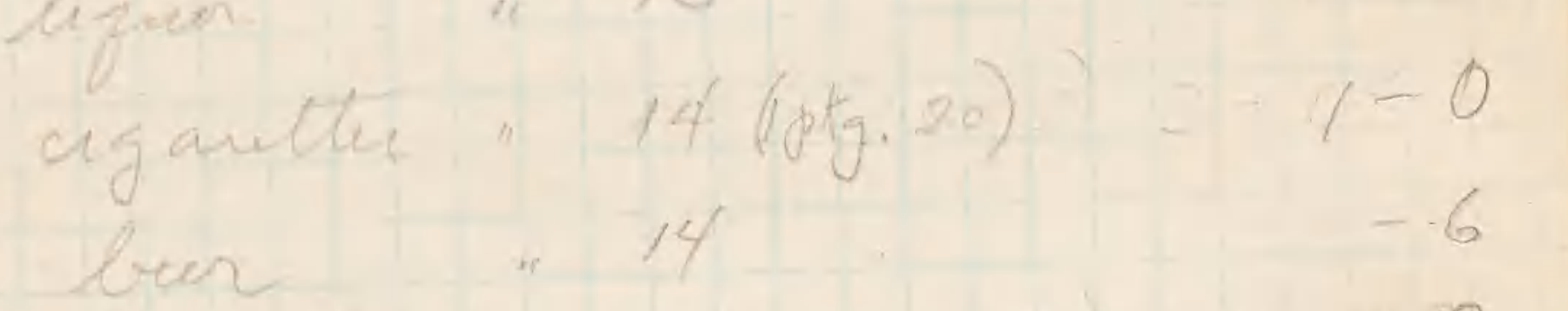

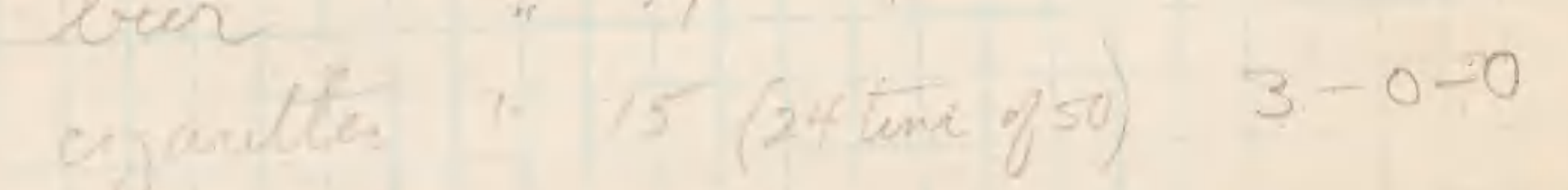

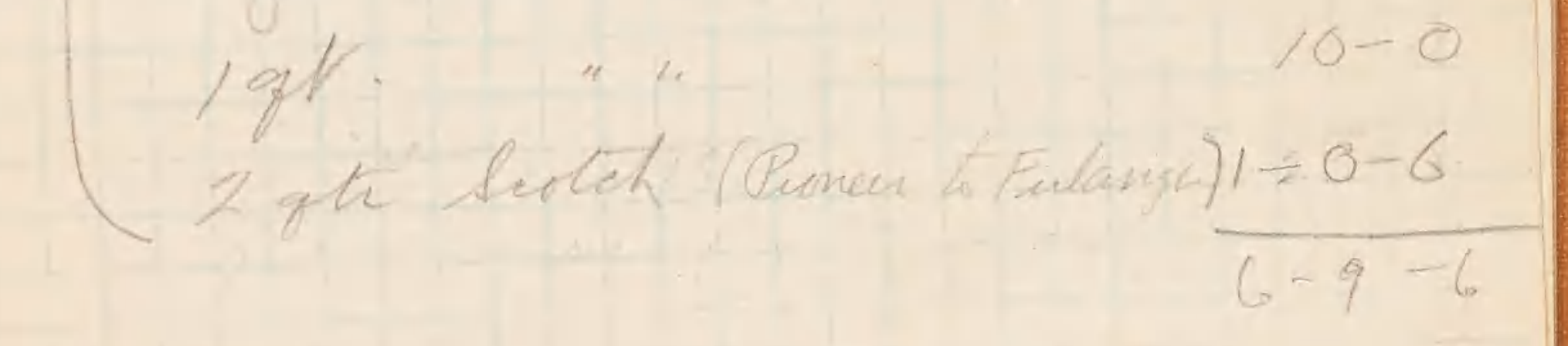

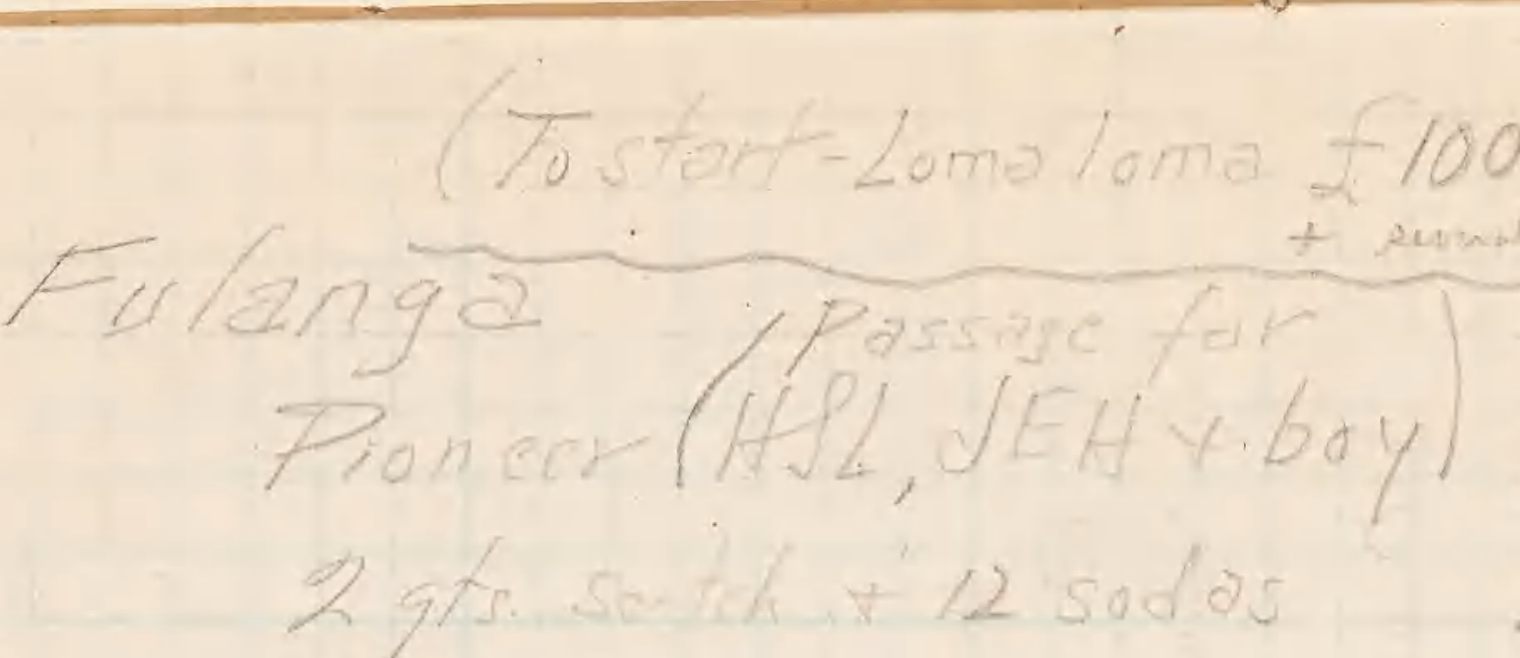

tips pianeer $6-6$

newaptin form Sum $12-6$

Sammy (2daye-Fol.26:27)

guade (Hel.23)

$\operatorname{arman}(1 d y)$

potage

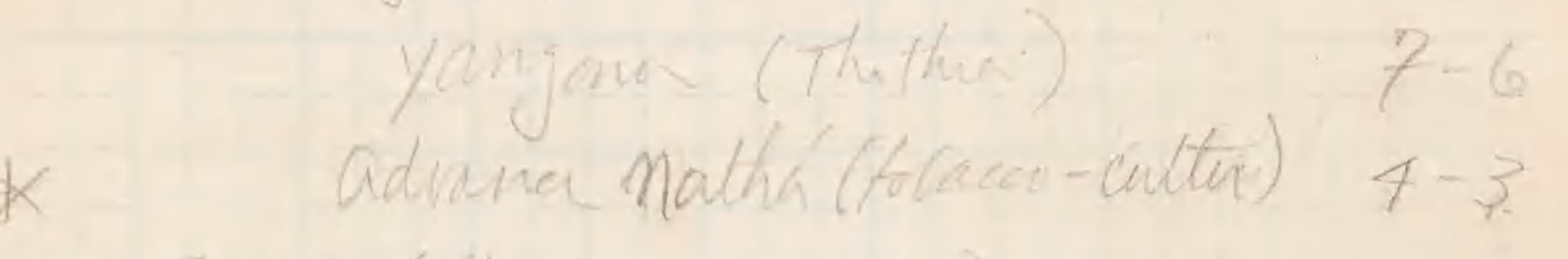
Fel. 28 (of natur catiul)

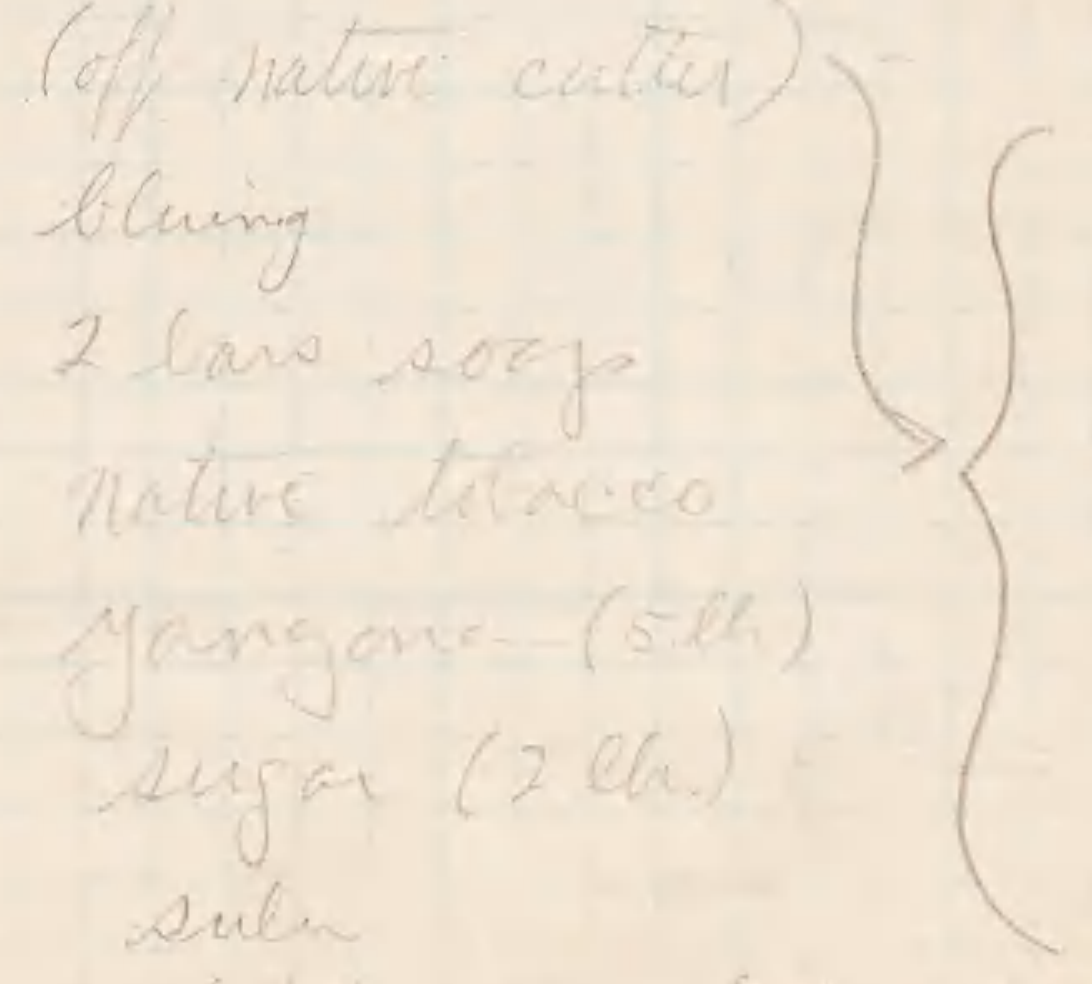




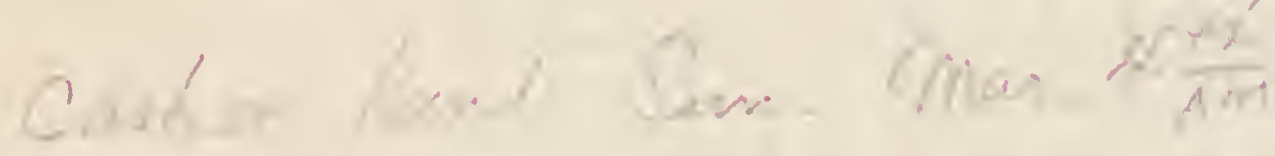

flomber

$19-0-0$

$5 \times \cdots+3-10-0$

Siliven

$$
\frac{1-6}{13-11-1}
$$

$$
\frac{4-6-7}{90-16-7}
$$
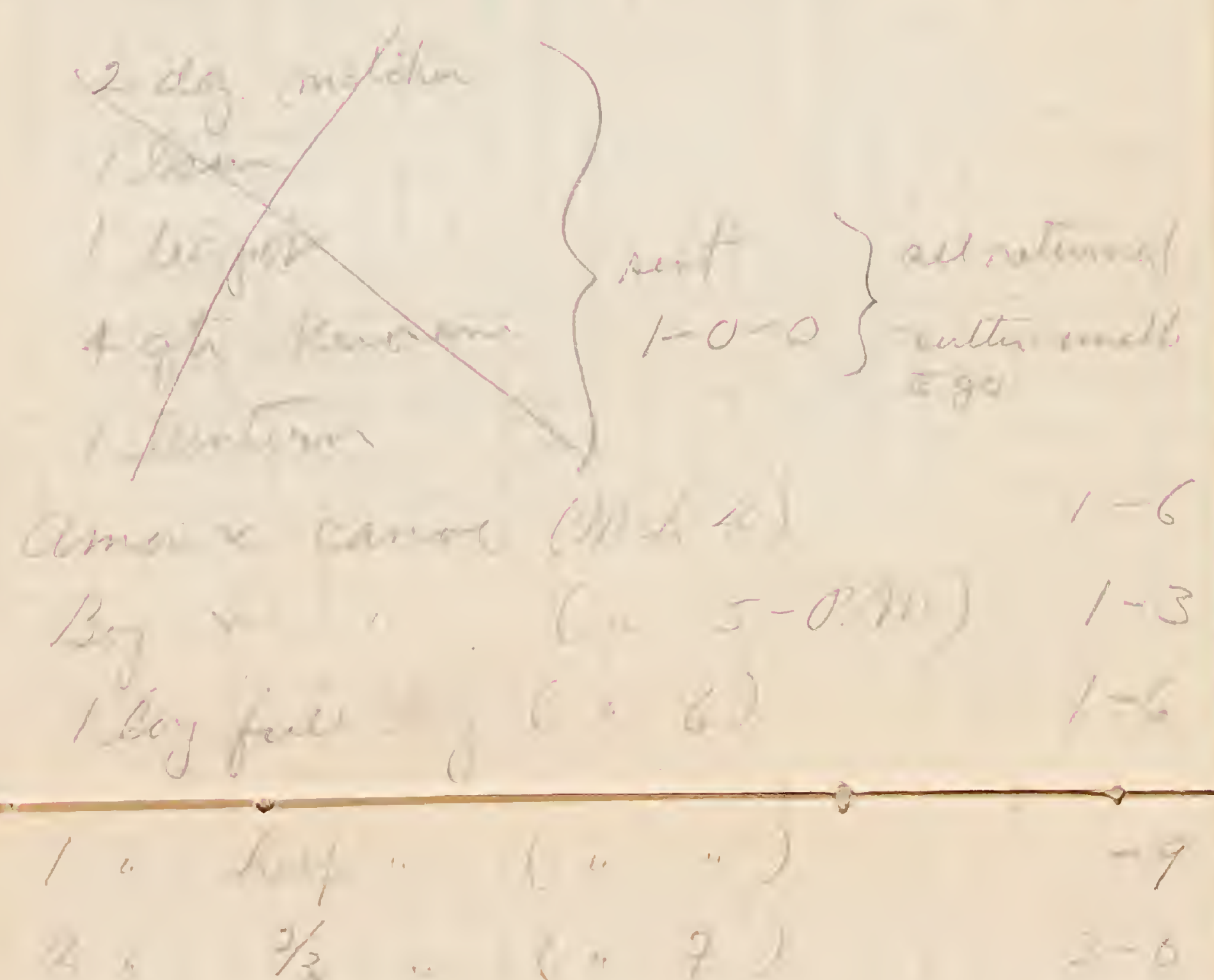

n.t.

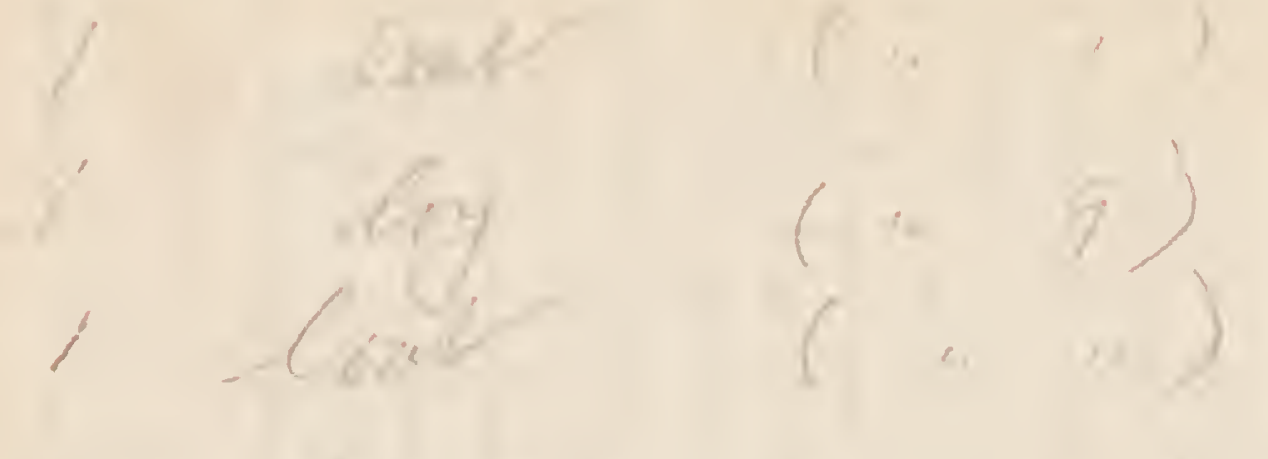

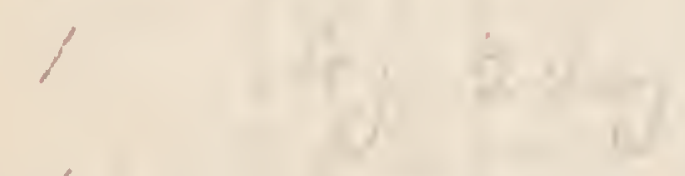

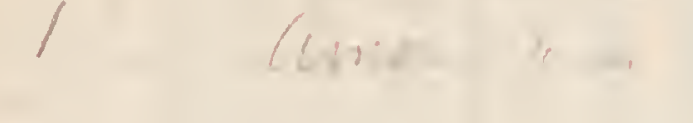

$1,1 \ldots i$
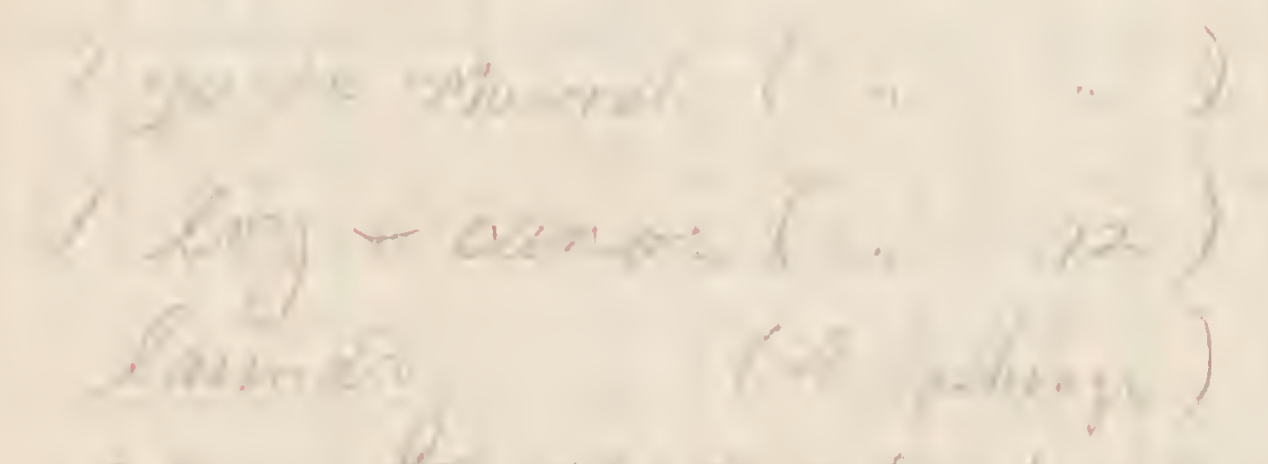

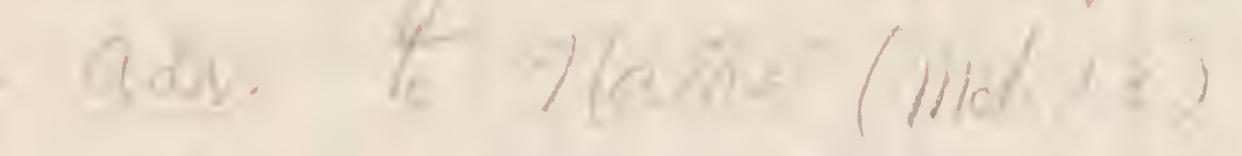

atson-aturan $(1, y)$

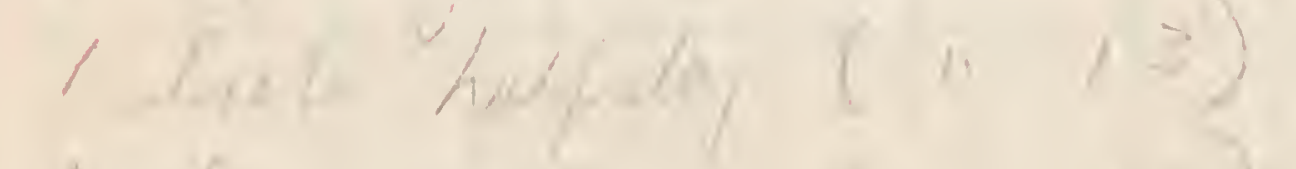

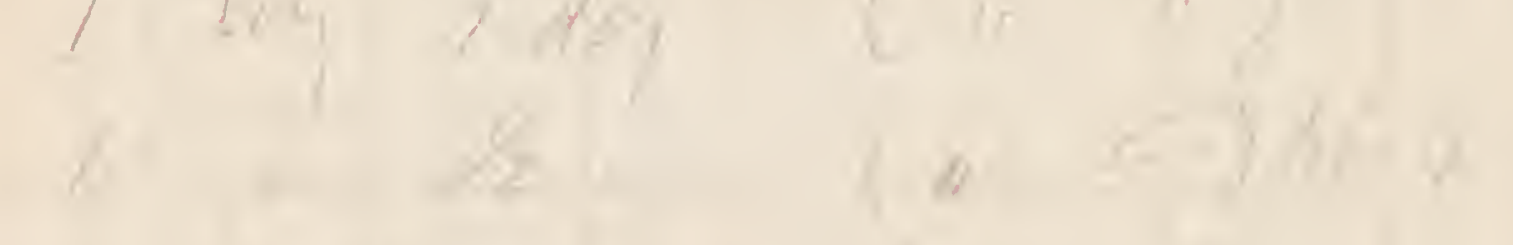




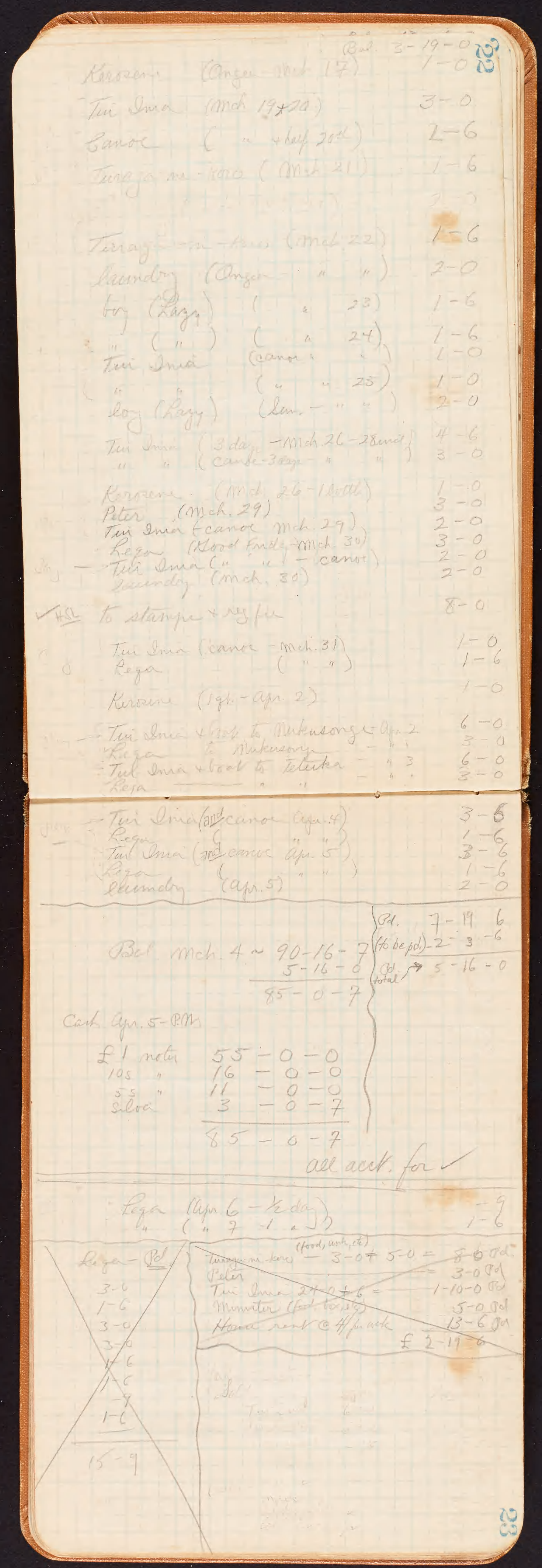




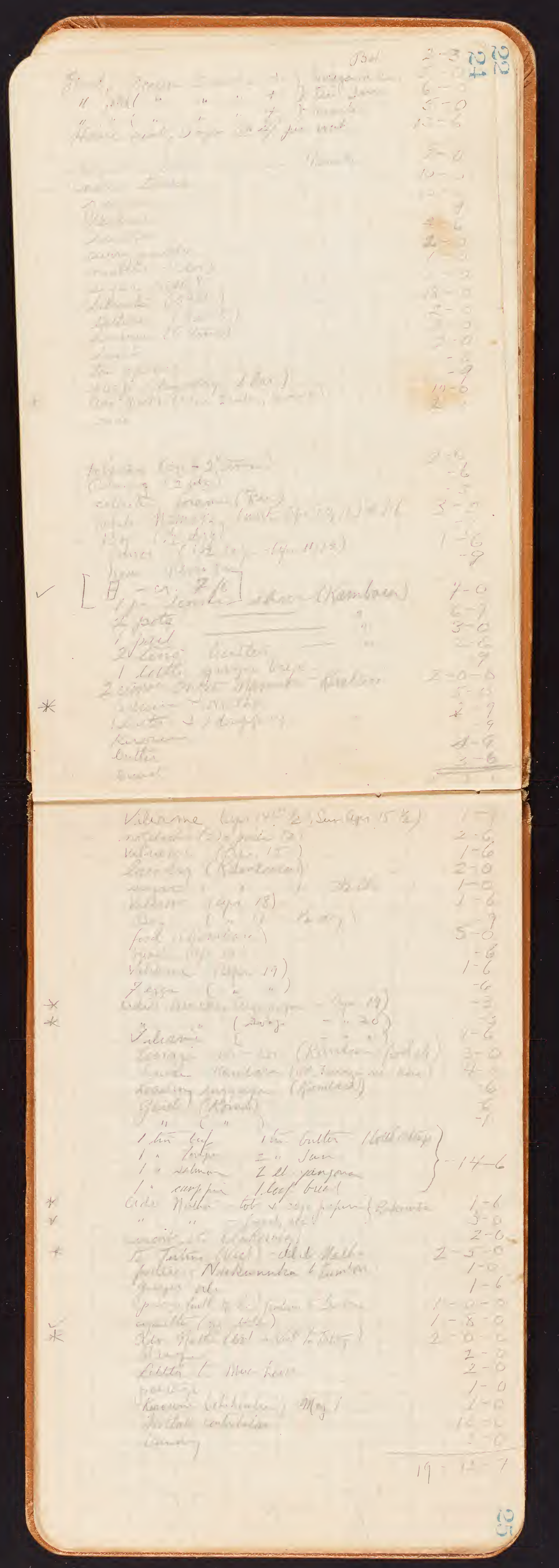




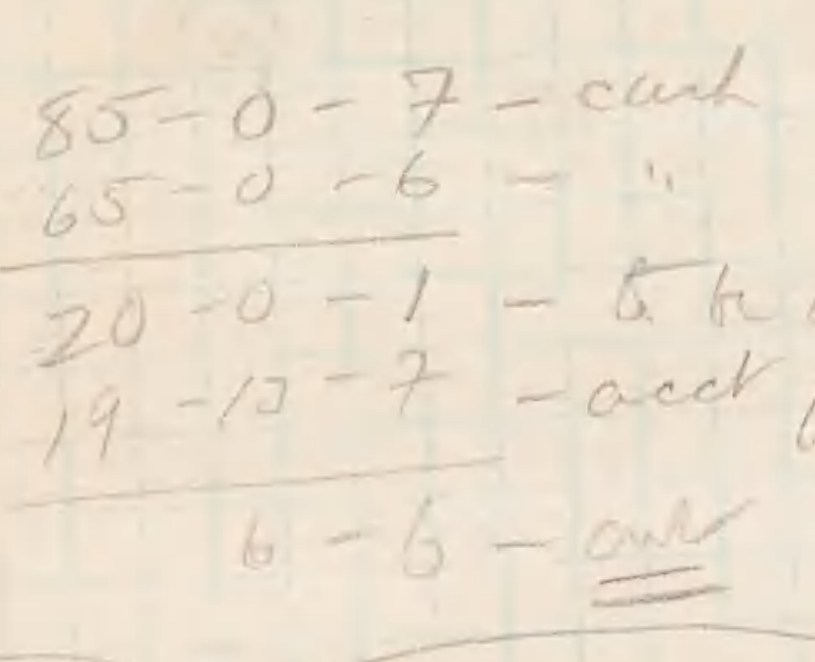

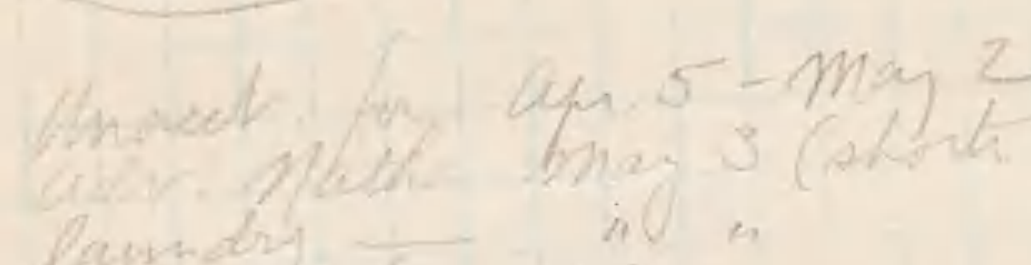

lawh

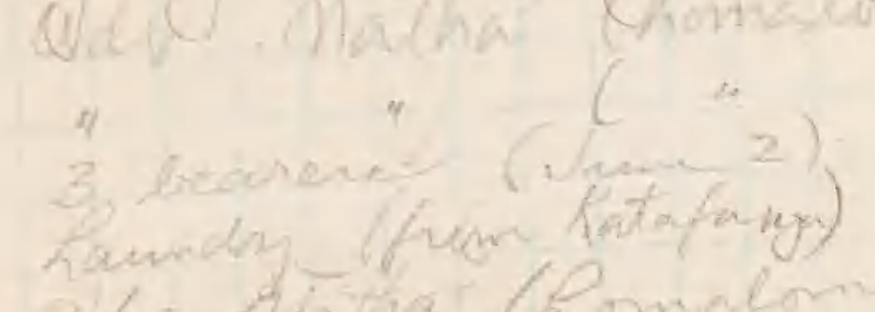

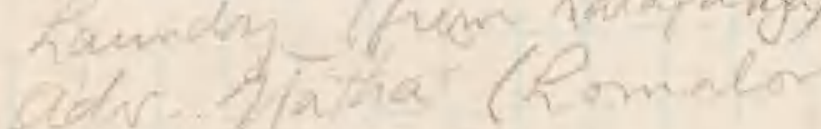

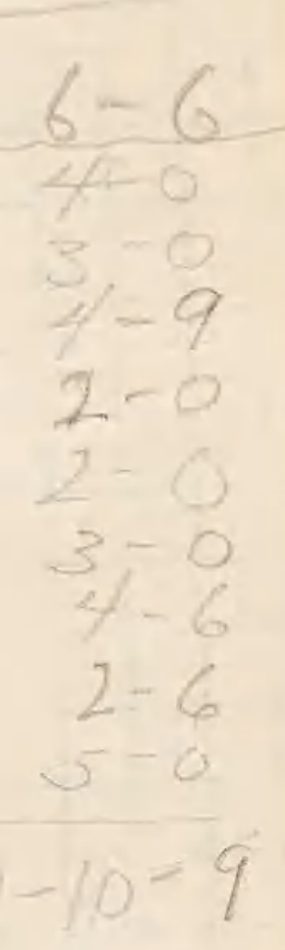

$$
\text { b }
$$

65 -$$
+\frac{2}{2}
$$$$
\text { (n) }
$$ 


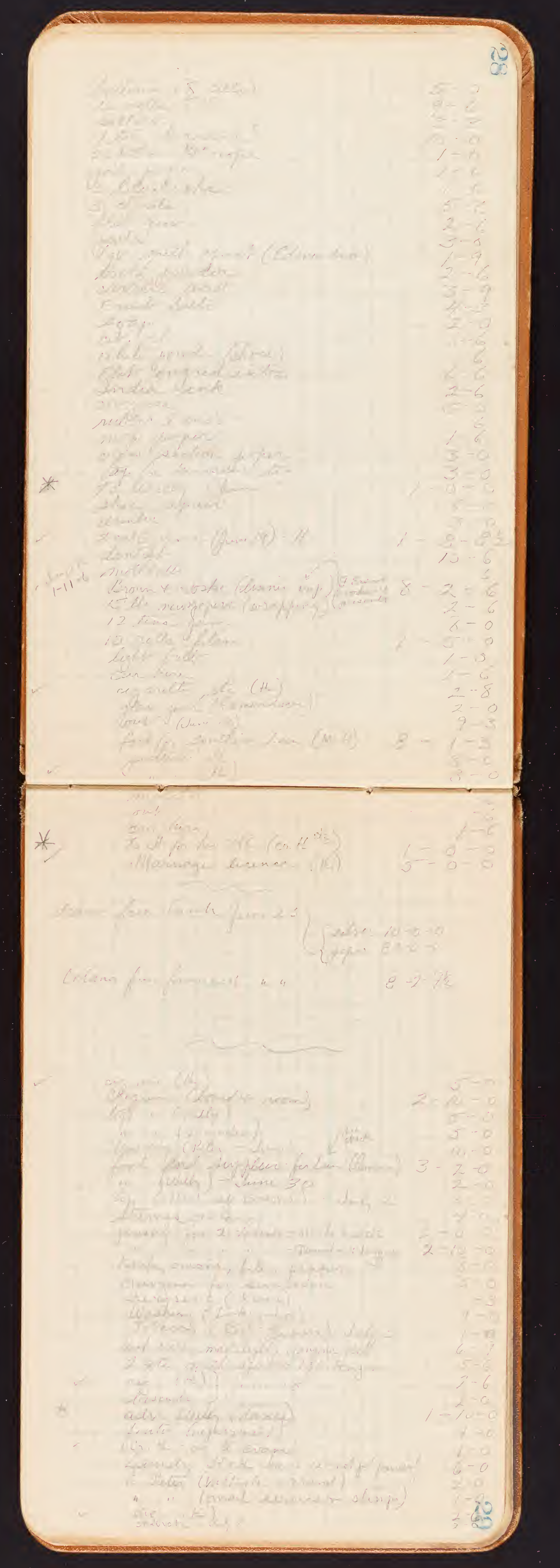




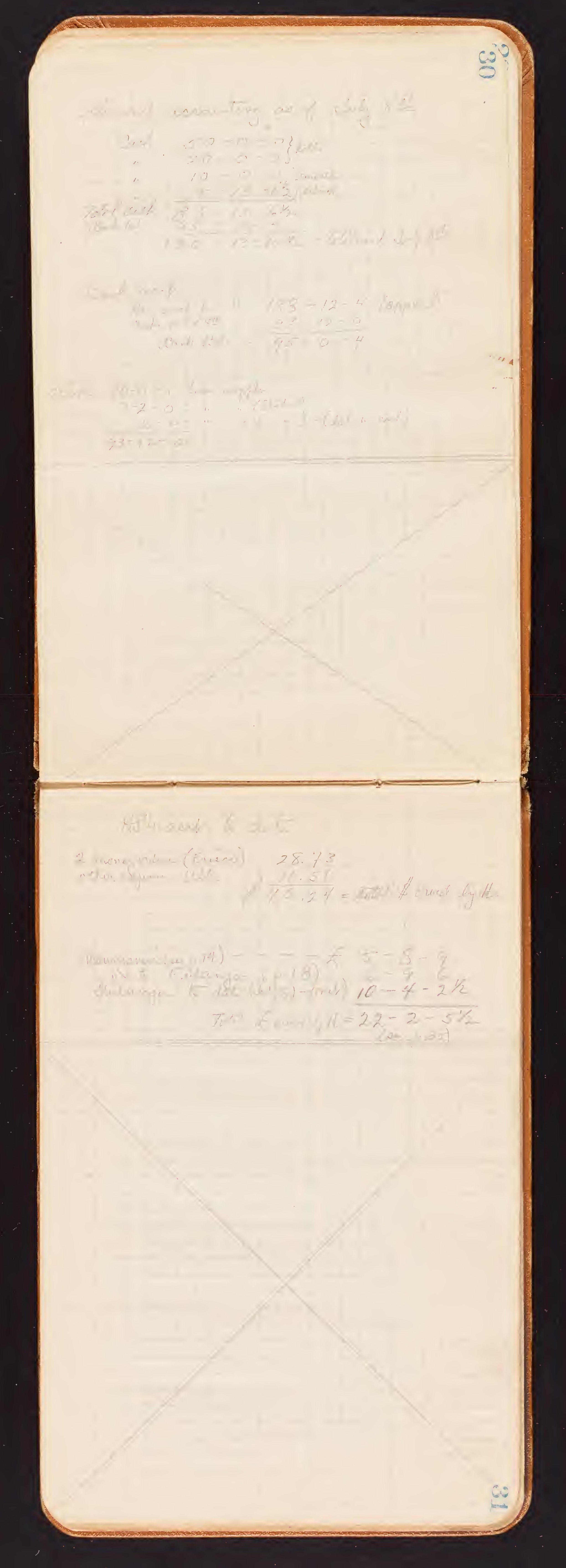




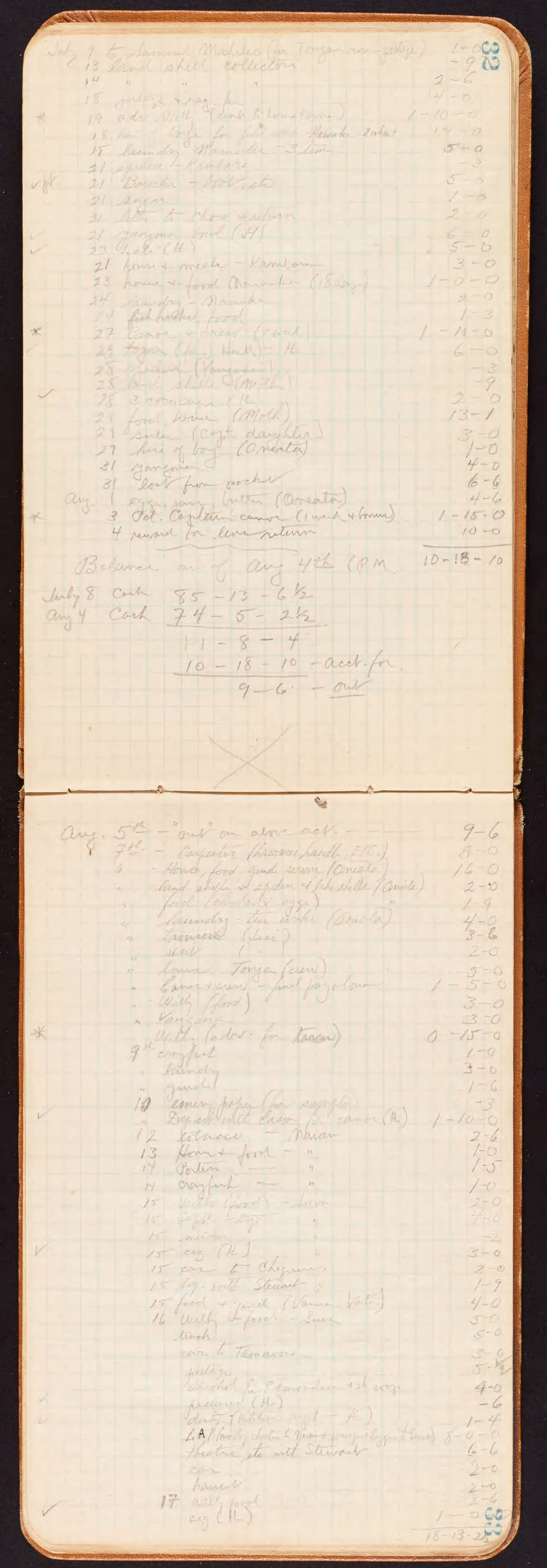




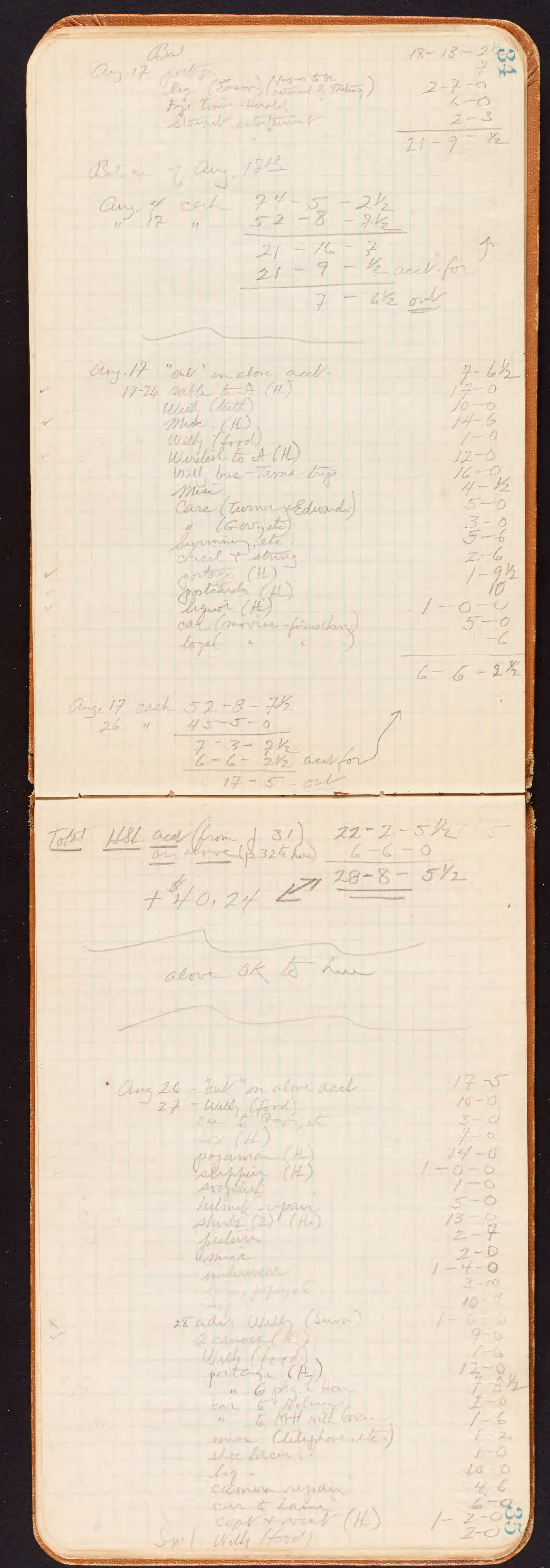




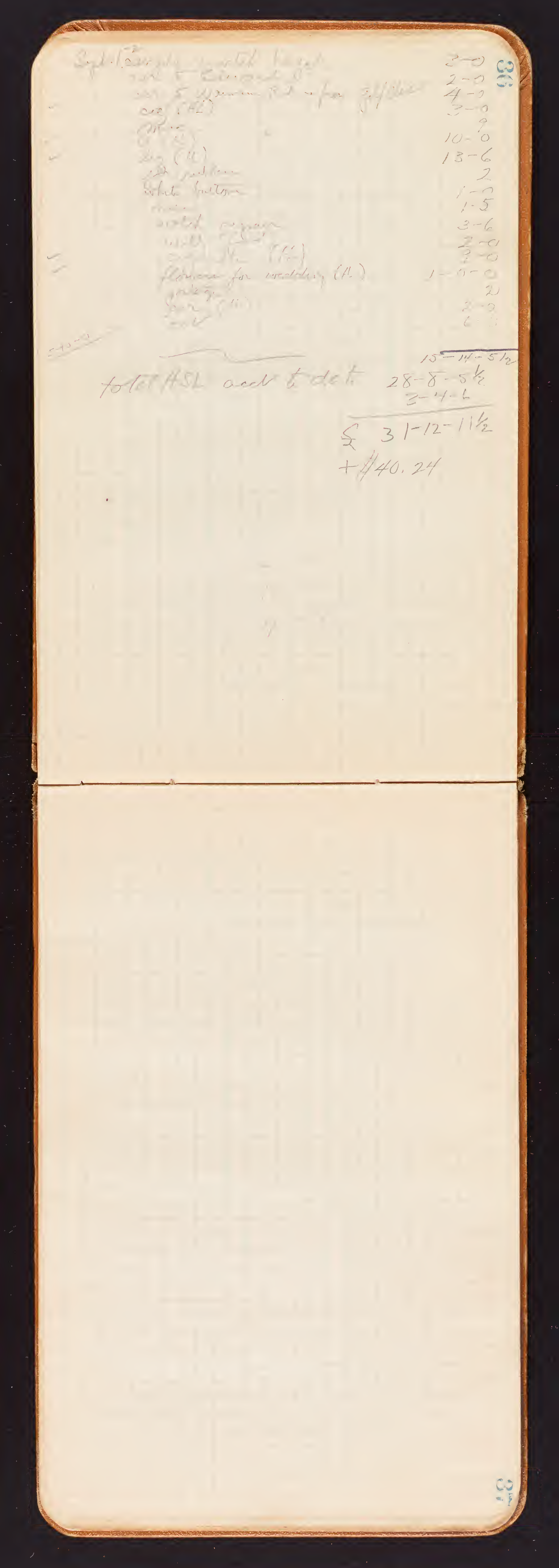




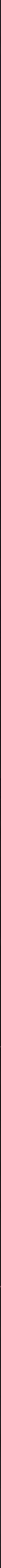




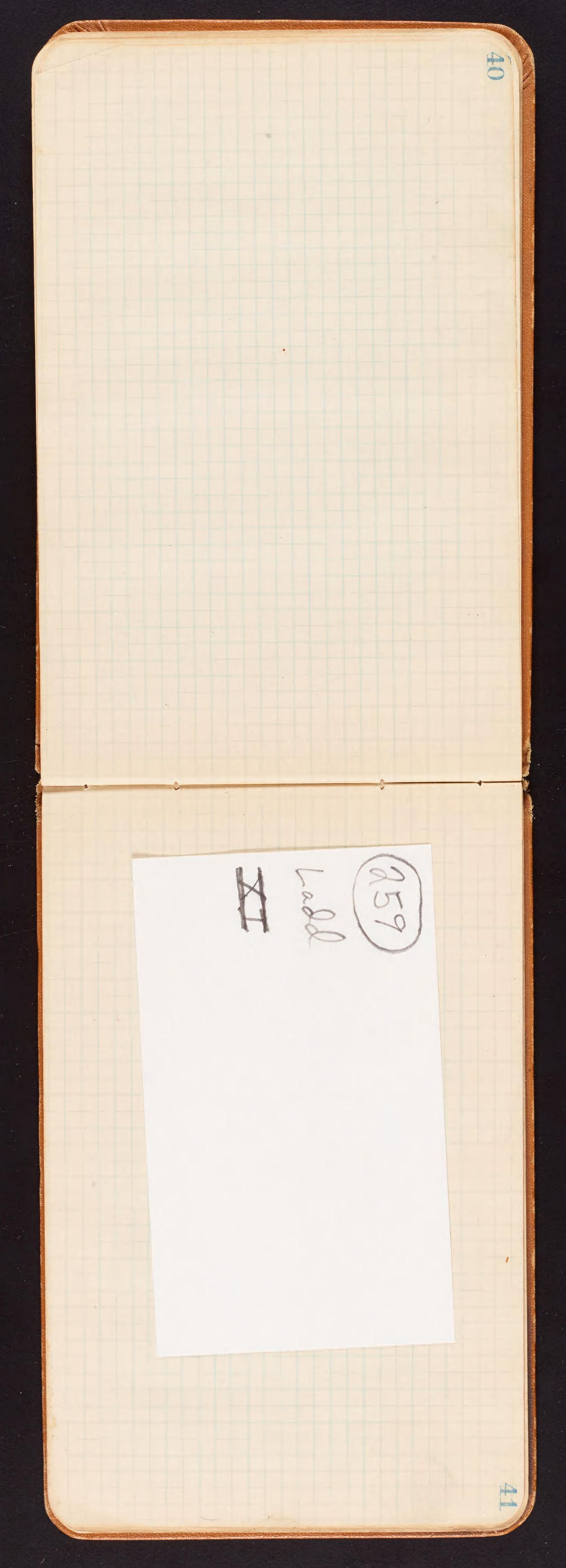


(259)

Ladd

$$
\text { XI }
$$




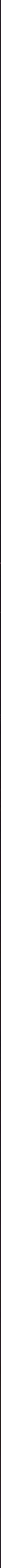




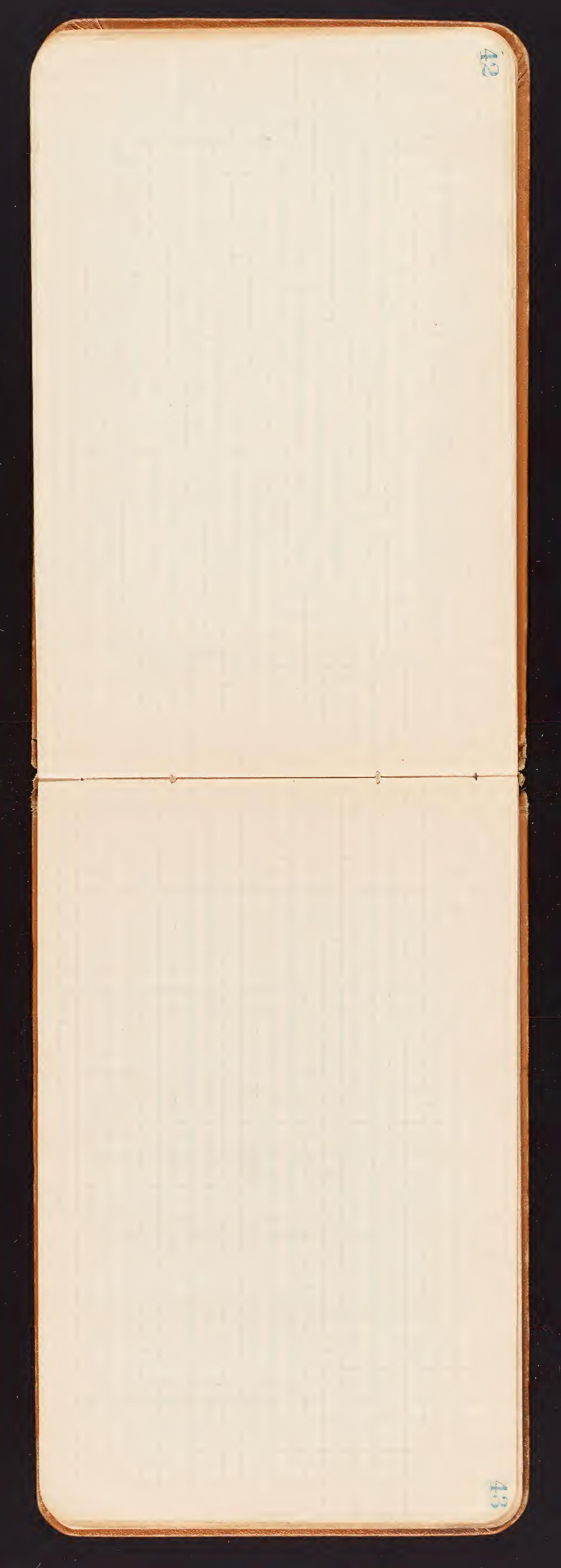




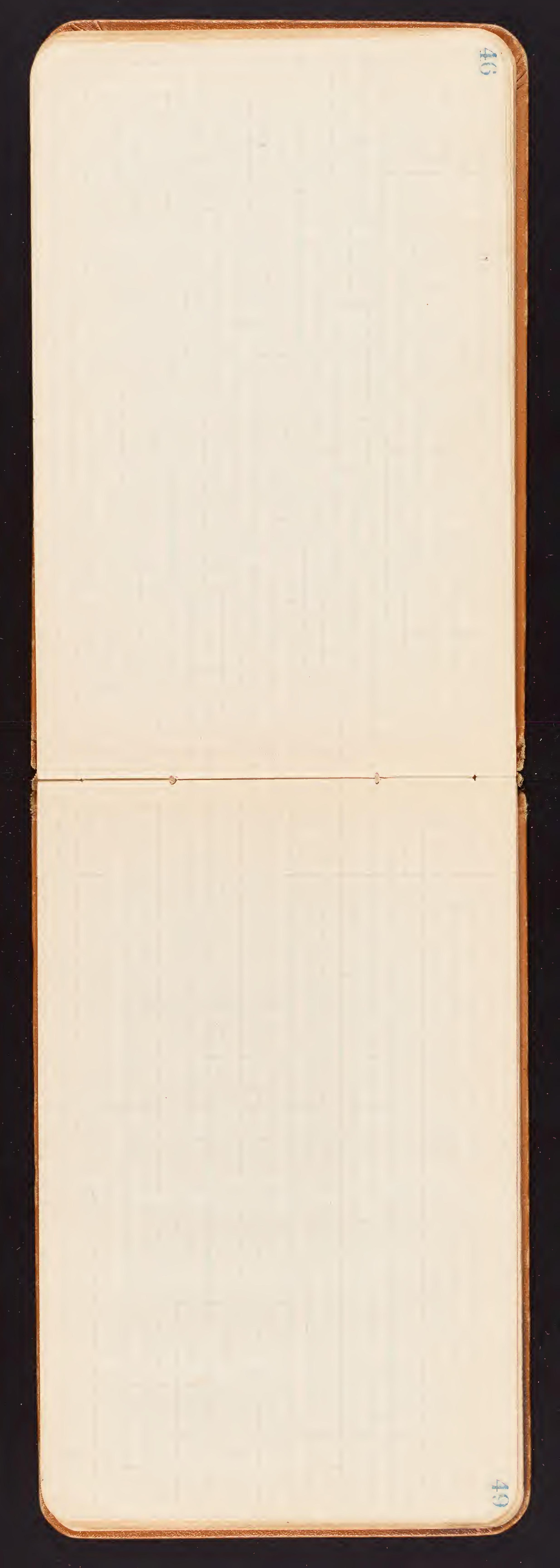


Thune fan 14,1934

hep St fome al $I \frac{45}{P M}$ on c*a

1. for Mander taig.

$$
\begin{aligned}
& \text { Gromgeal to Santa te at K.C. Gowno }
\end{aligned}
$$

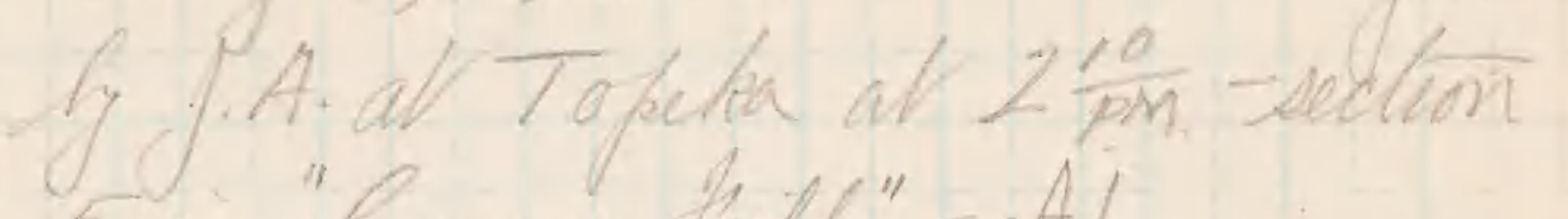

$$
\begin{aligned}
& 5 \text { in "Corgus Field." - Al. }
\end{aligned}
$$

Lat. Jom

13

A. Levere at hamy at $12 \frac{35}{7.4}$

$\sin$. mu

To fre Angele a m te $\sin$ Airgo,

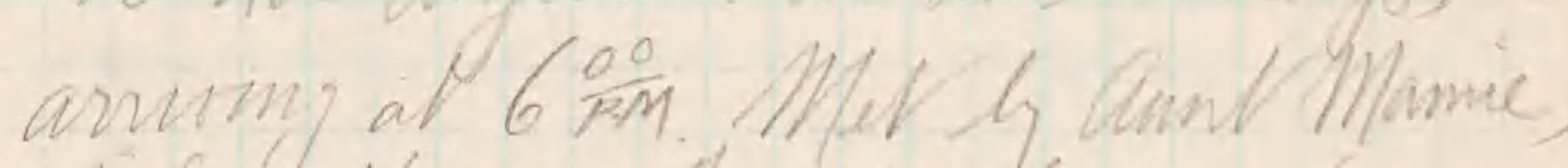
tom Alul y thank thromas cencin

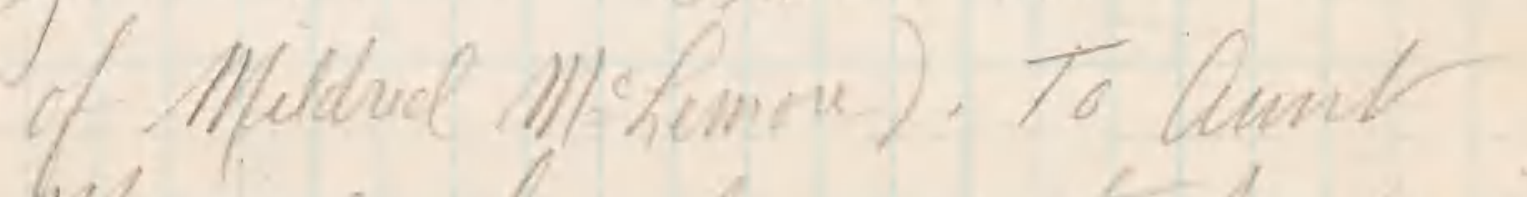

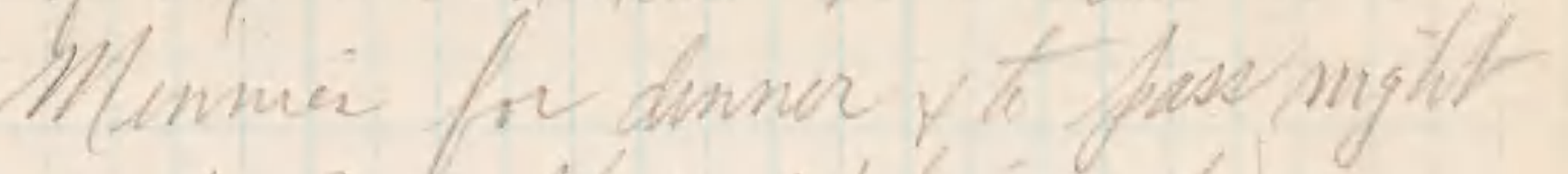

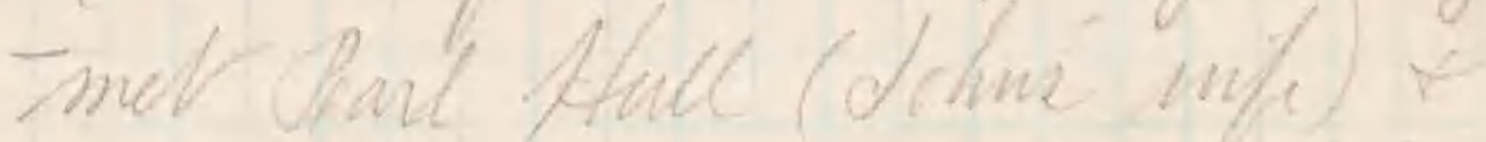

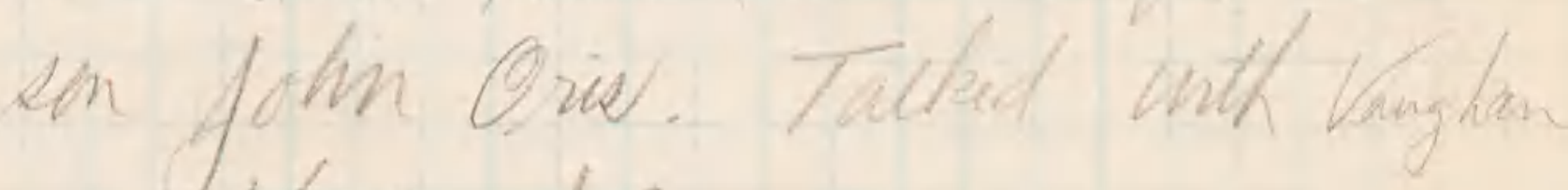
on phone A2. 


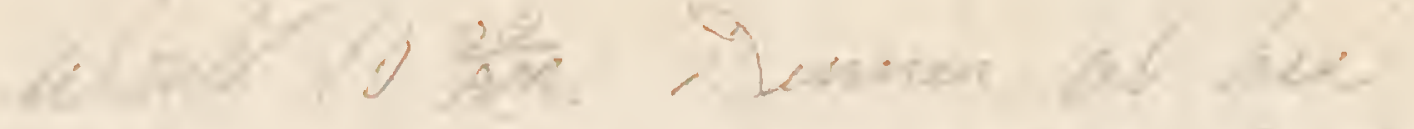

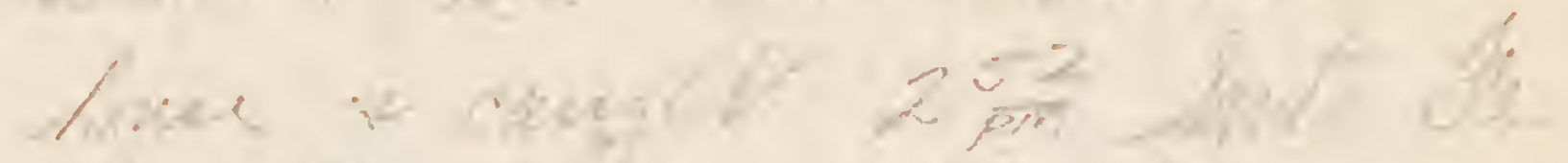

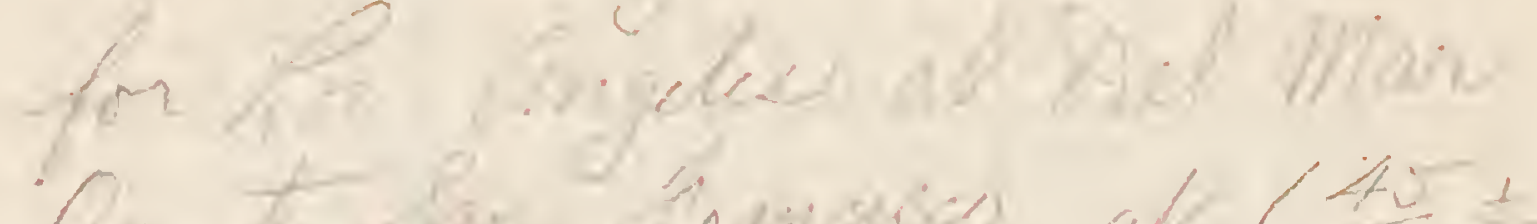

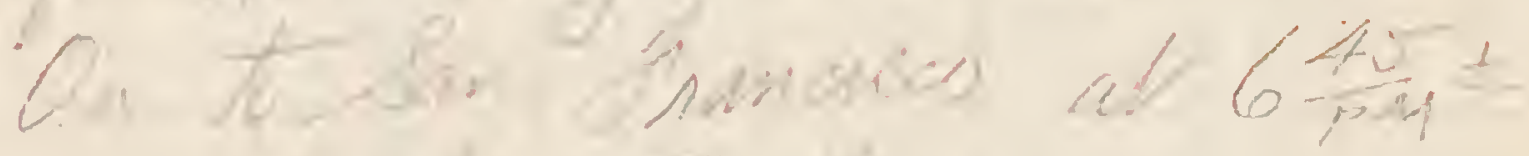

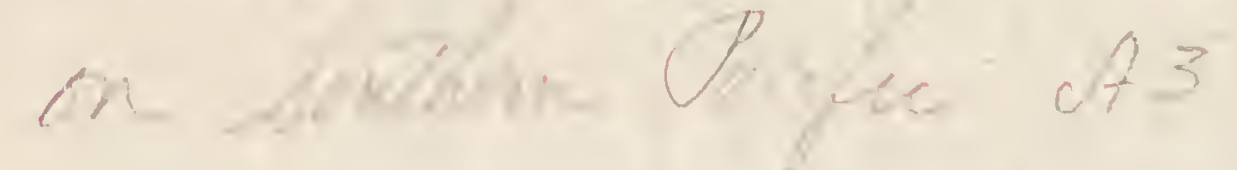

Thas yen 16

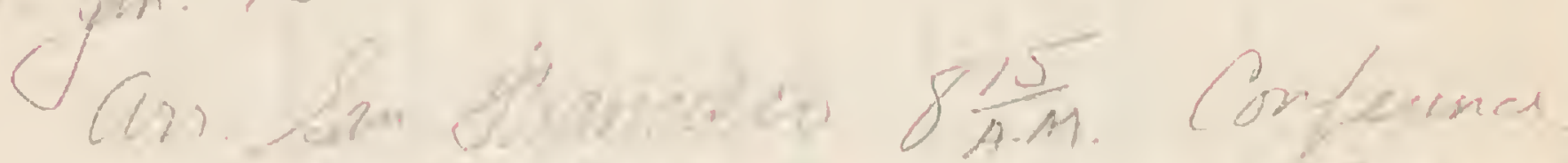

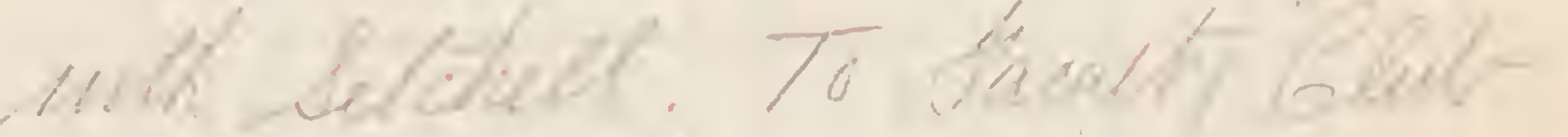

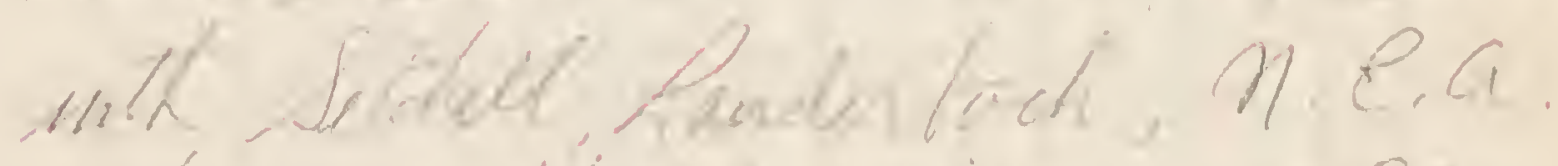
Alunde Abud Willame Ed

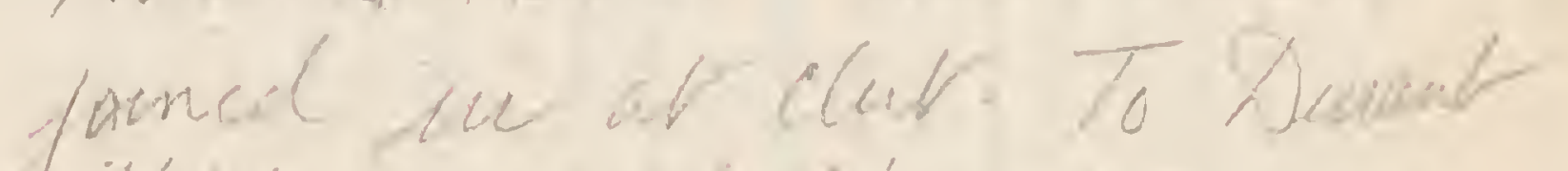

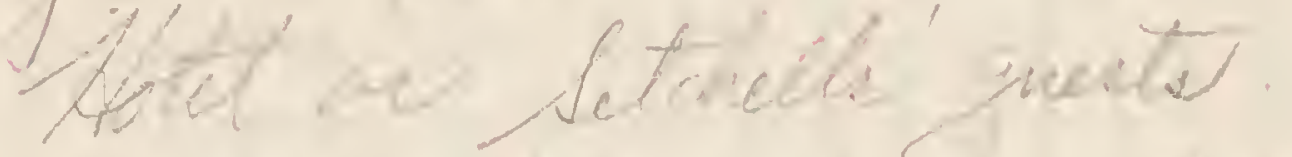

$$
\text { Mllec enende in U? DII. To }
$$

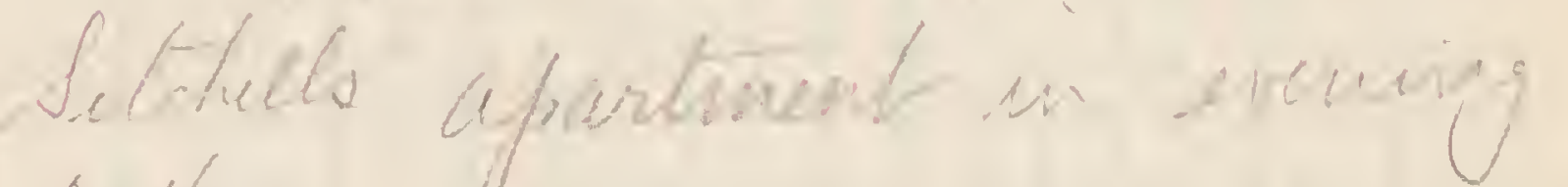

M. A H

Har $\tan .17$

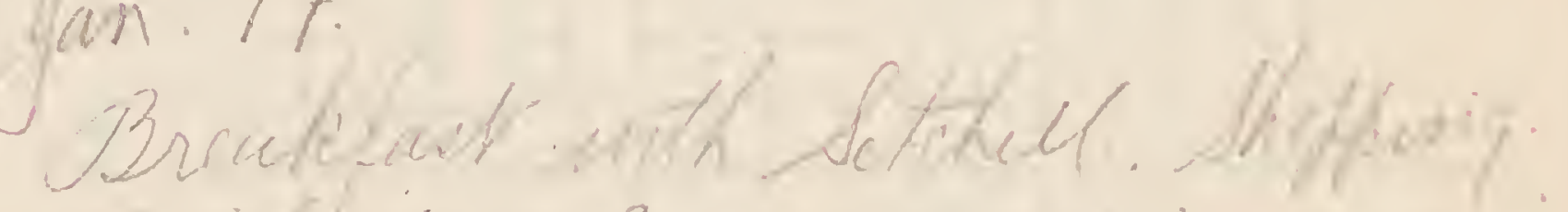

There. lan. 18 .

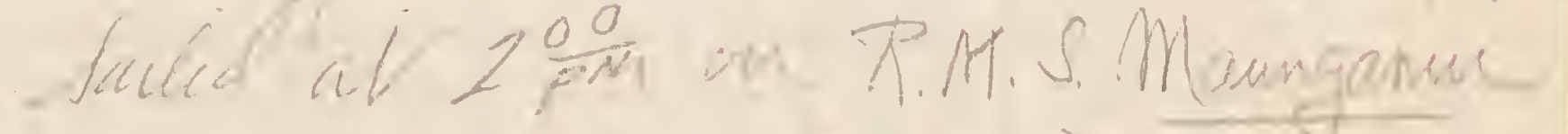

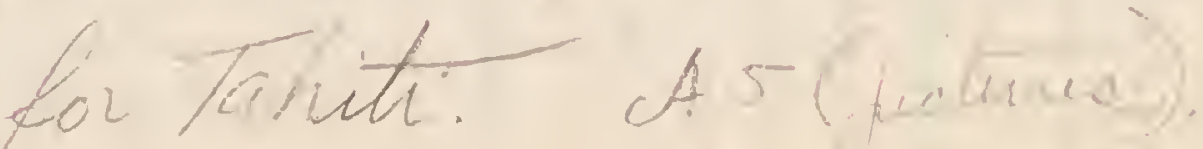




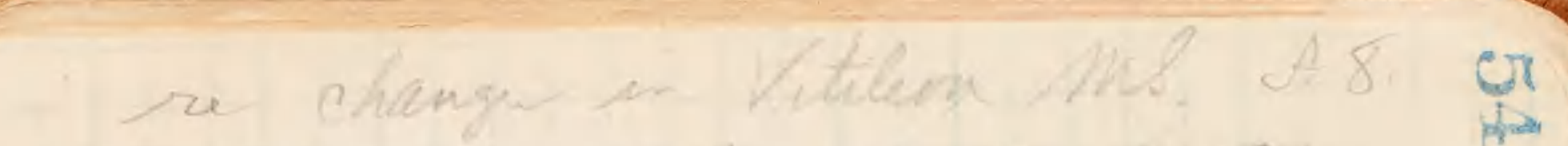
Powed twatrie at alwer pon unew 4.8

Lat fan. 27

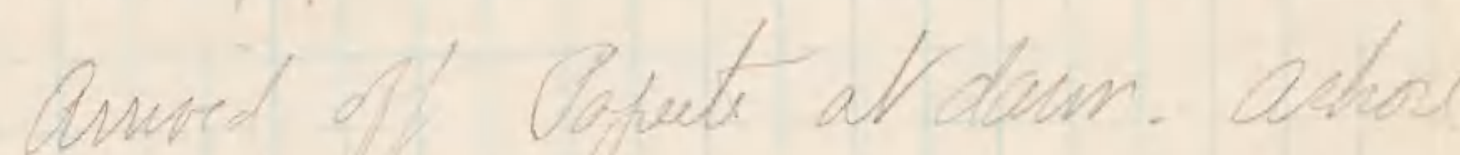

a) $\sqrt{\frac{B}{A M}}$

$3.12, X I 1)$

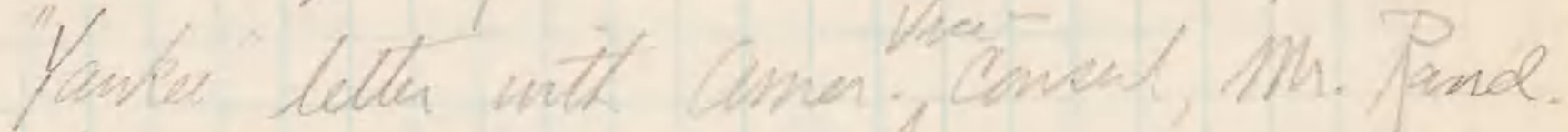
Swet at $5 \frac{00}{p+n}$

Sam $\tan \cdot 28$

doy. Jhis noten a ht (A9)

N1/. $\tan \cdot 29$

$$
\text { Sighed Parolonga alom } 6 \frac{30}{A M} \text {. }
$$

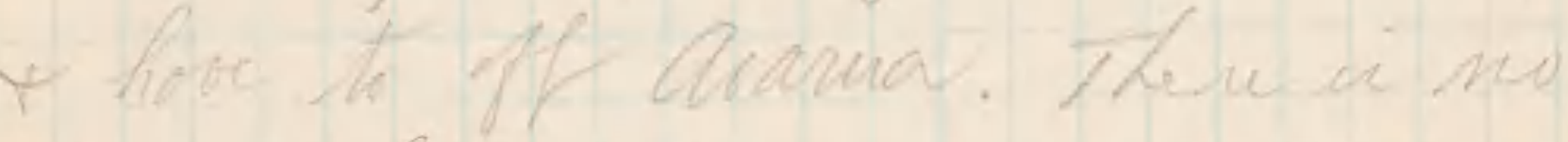

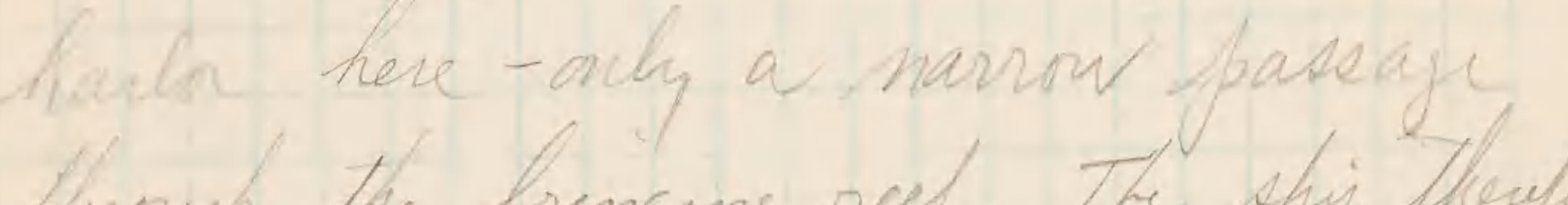

twowh the frenging seef. The ship therfor

litgo her andur $x$ drefted tonand shou

witel the andere took hrel on the

deefig simken edge of the reef. Tradid

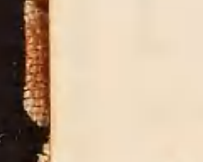




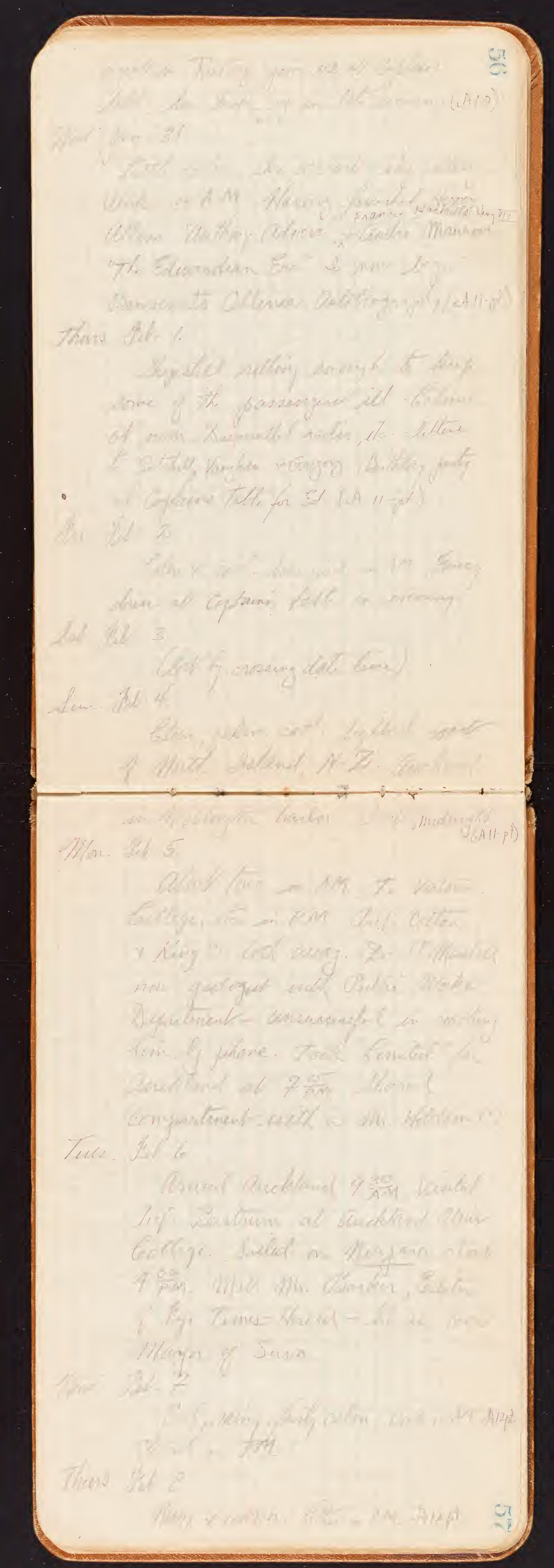




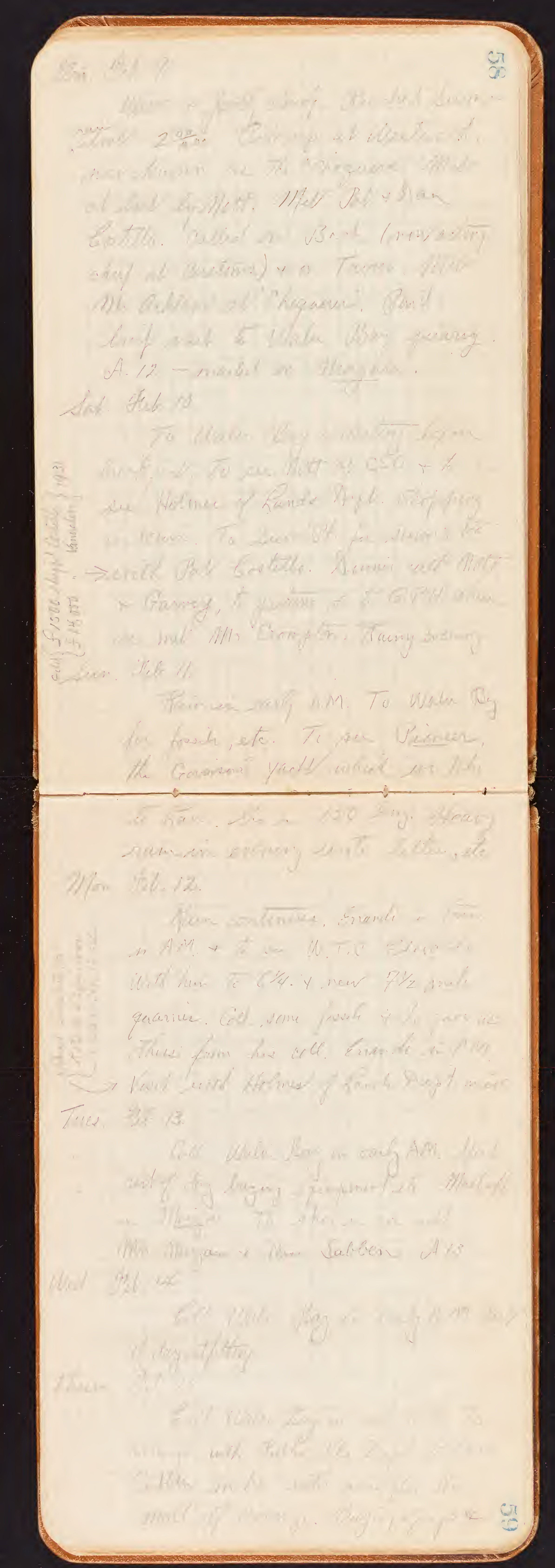


wet Mn.t Whe. US.T.C. Edwonds.

this. Hel. 16

Dimir at Pion Hotet with Xi. Smith

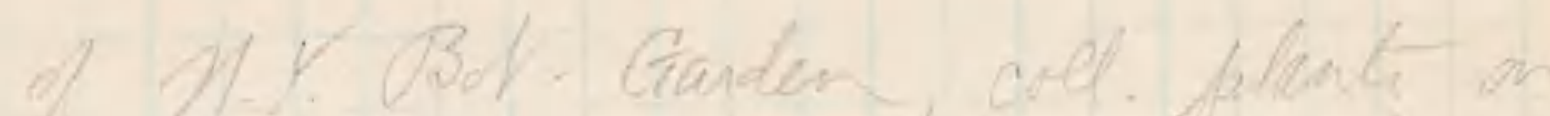

B.M. Houstaijo. Dl chequen lata

with Pure k Mhen. Alemming

Lak. 2tek. 17

boll. al Walu Bay in each AM

Tested unter samples birid Natha

(Mathaneile

of Roto. Saild al $2 \frac{00}{p}$ on Peoner.

an. Tick 18

Lleyl on deck.

Galm, doudy, wamm.

Mon. Jiel 19

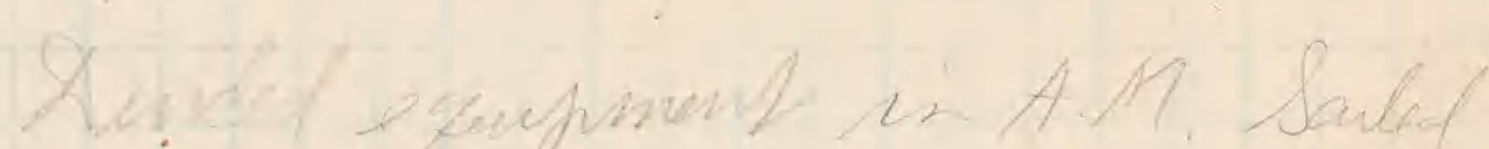

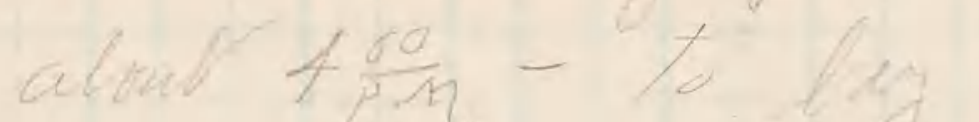

? - / / 86

Delant

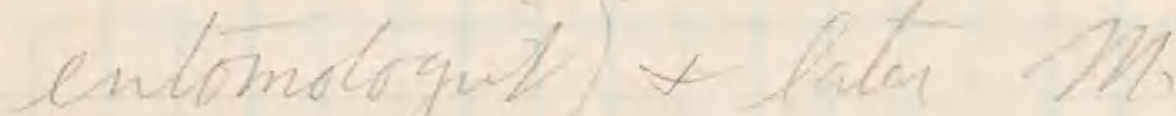

Twe

to Thitue - oftermote

Whe

crml seath of Tas

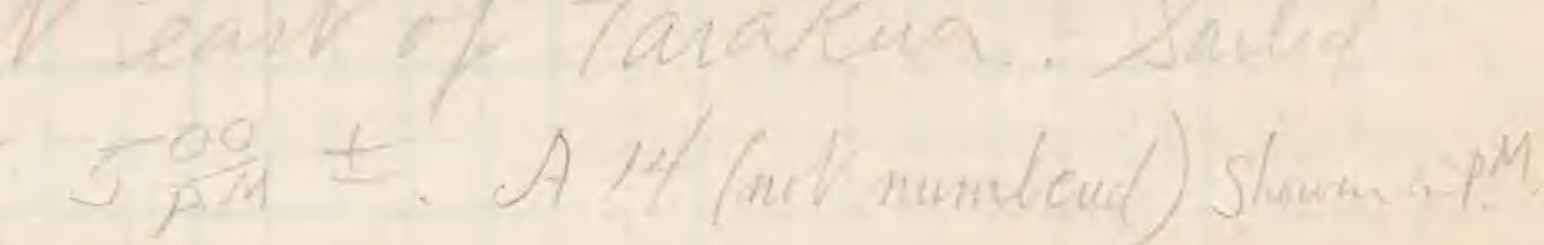




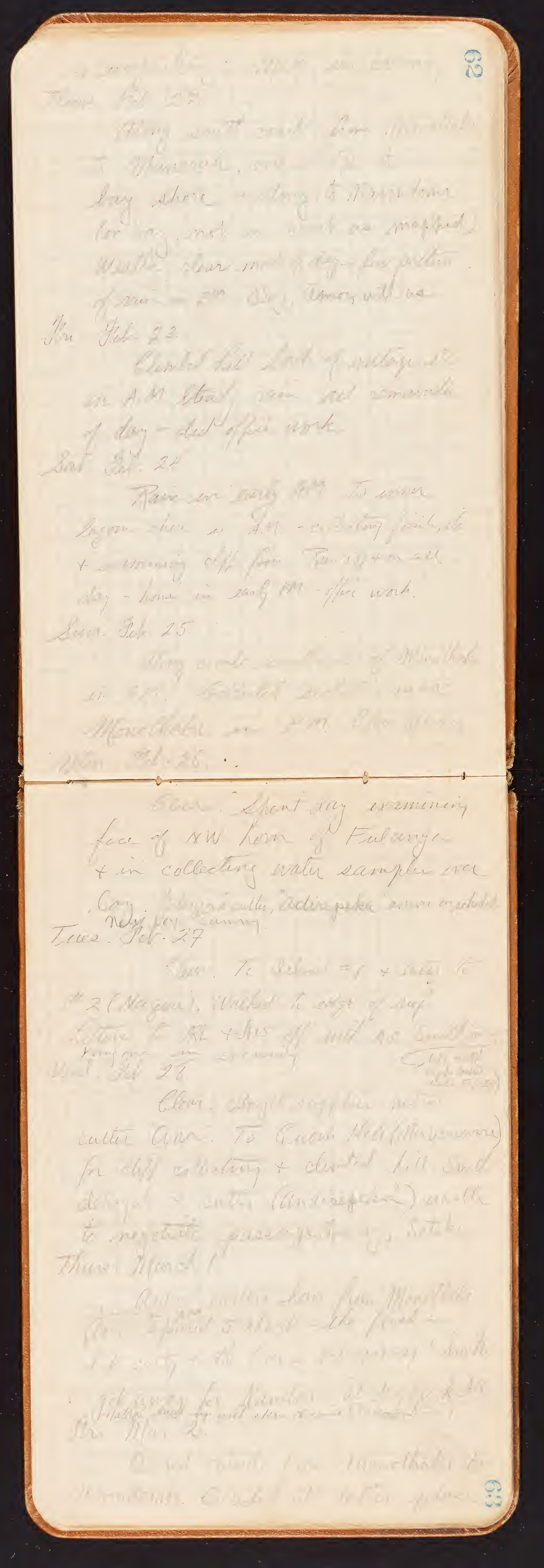




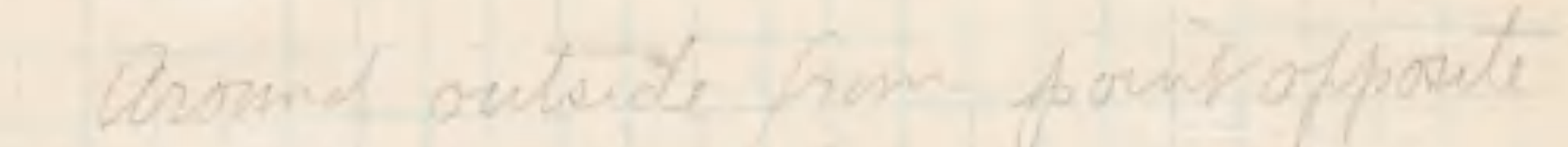

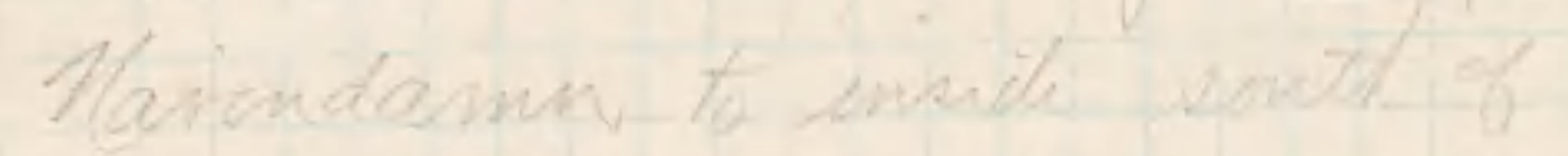

Quom thil . Tested latom samph

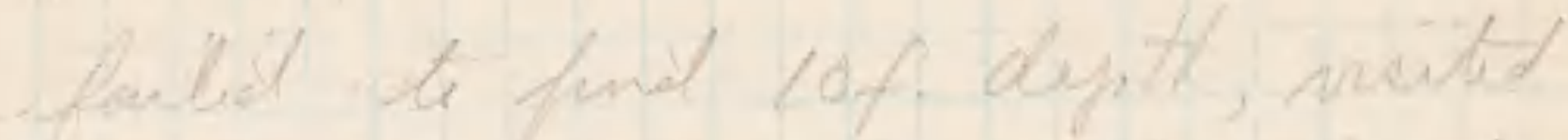

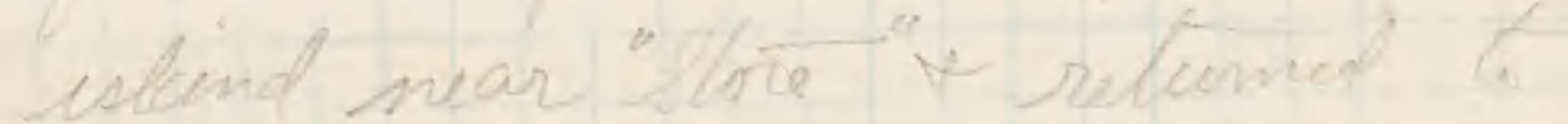

Alonothater

Toulinga end to te on Mothe

Folve here nest wak.

Sun. Nar. 4

$$
\text { Qfou wath in A.M. Govecting }
$$

in $P M$.

Mon: Mar. Sth

$$
\text { Thaver in AM - made Onger: }
$$

enturgenent. belecting to unduand

in PM.

Tues. Whan 6 th

A.M.; south covil of log wat of "storo"

Wed. Whar, $7^{\text {th }}$

in P.M. Heary rain all mith

wact

Wade dectern of hel wonth of "D"

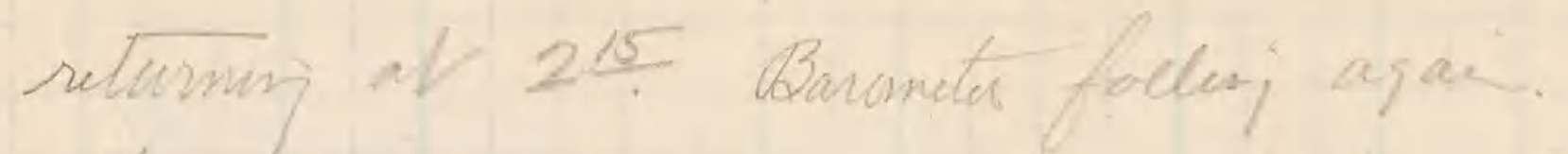

Hear the Tentionge Aandel youterdey mi

Mawindama. Qfea wath in PM.

Thure. Nfor. 8th

teang ram in early a.m. onit

Whaver vent of day. Mad mapof

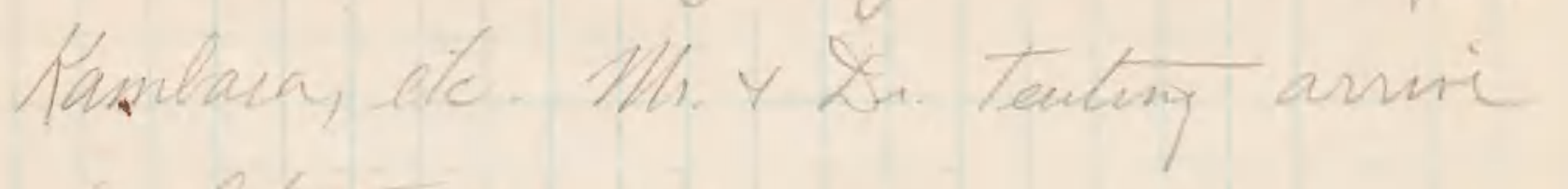

in late srosming.

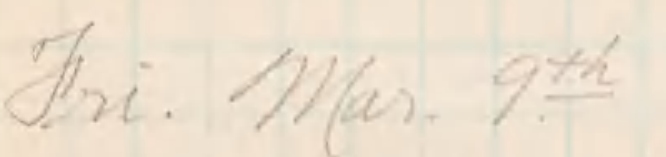

Shomen at interialz. Blembil helli

$A+B+d d^{2}$ wat on SE hom

Sal. War 10 th

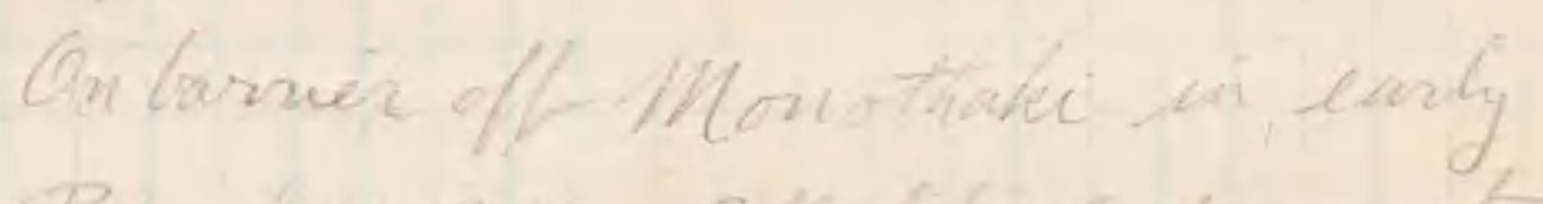

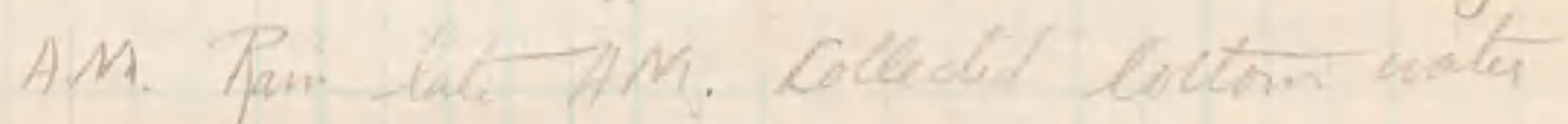

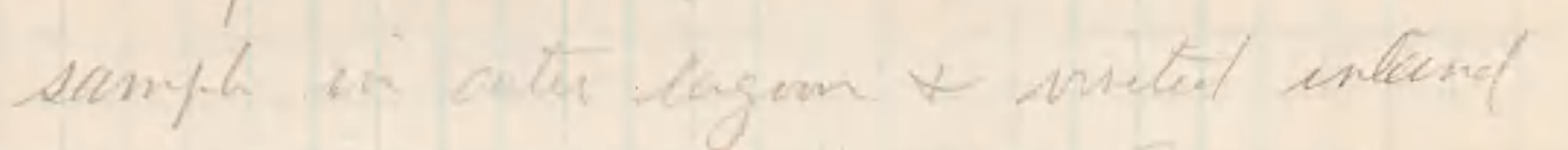

fein. Now. II.

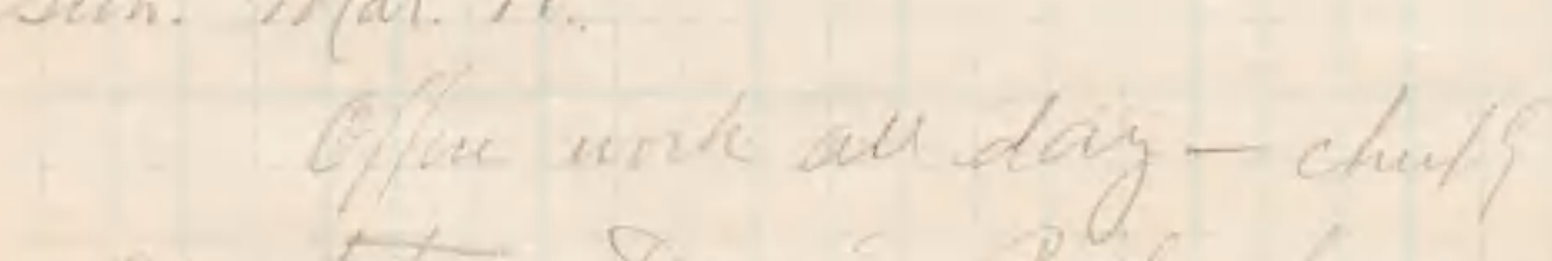


Qudure in eanf AM. clembel

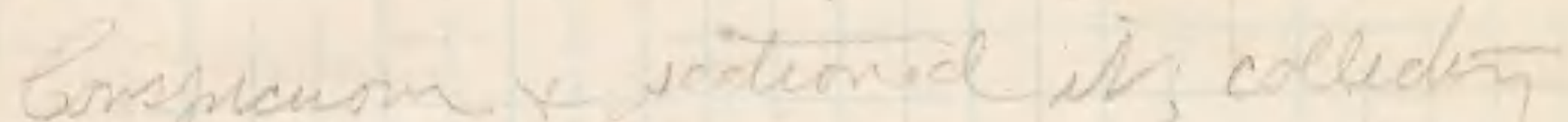

at Qula qila, home allet darh

Twe. Nch. 3th

Clagon A.M. - watu santh

in Muneral cave paderñ seto

in P.M. - Heam showen oft

Whol moh Qhyth

Heary rem almorl centumaraly

derdan truable to lear for Onges

Made map of Wangara, de.

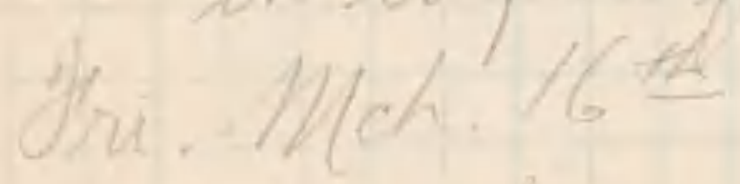

Sct Mch $17^{\text {th }}$

nullage

Lum. Nilch $18^{\text {th }}$

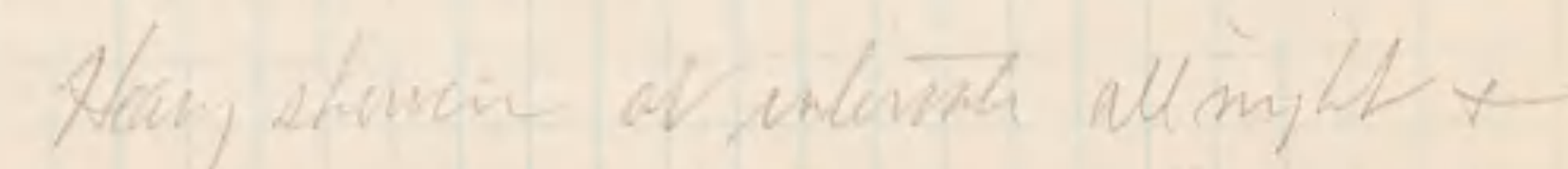

wall momming: Able to do fued wath

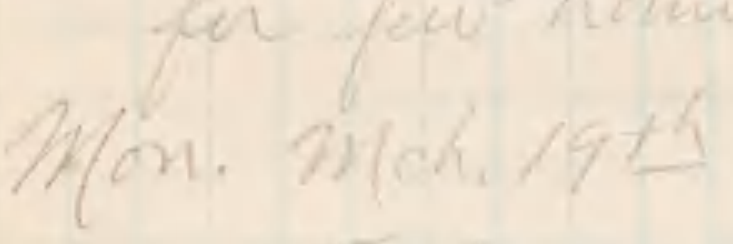

To Cugar Ut

anta

Tur. II/ch. 20t6

$(417-20, \pi d)$

$$
\text { Stagr an NE. A }
$$




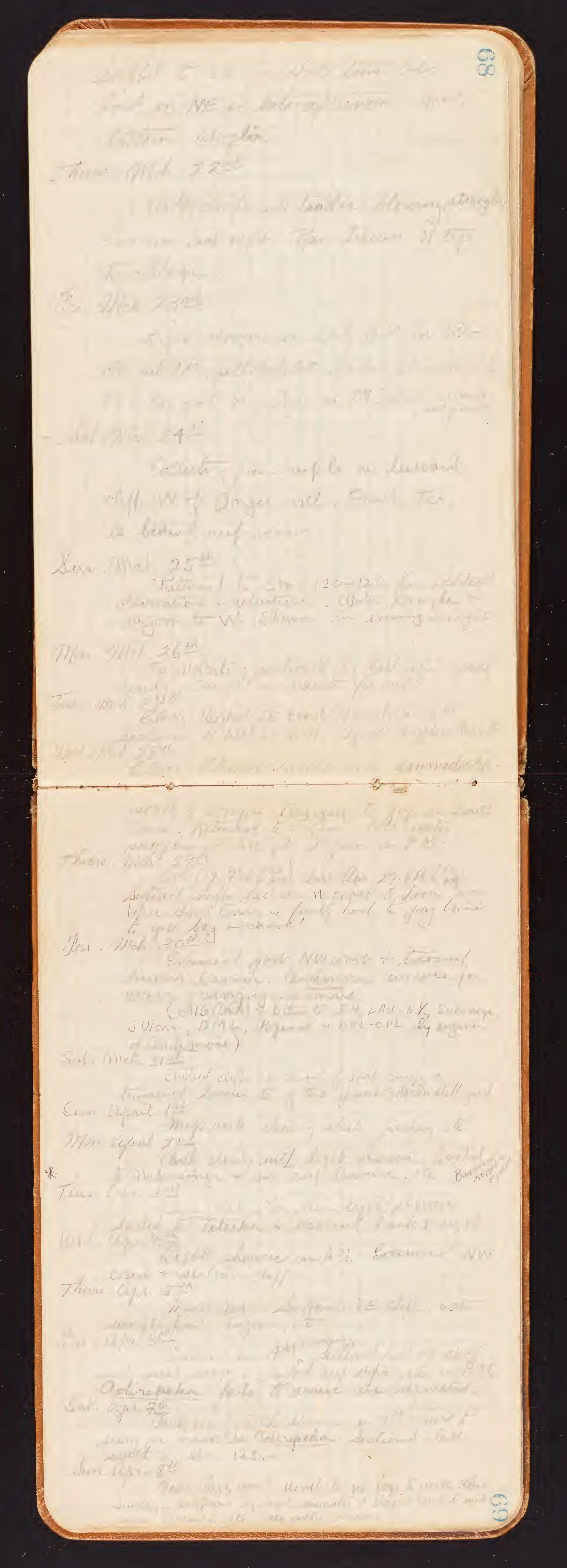




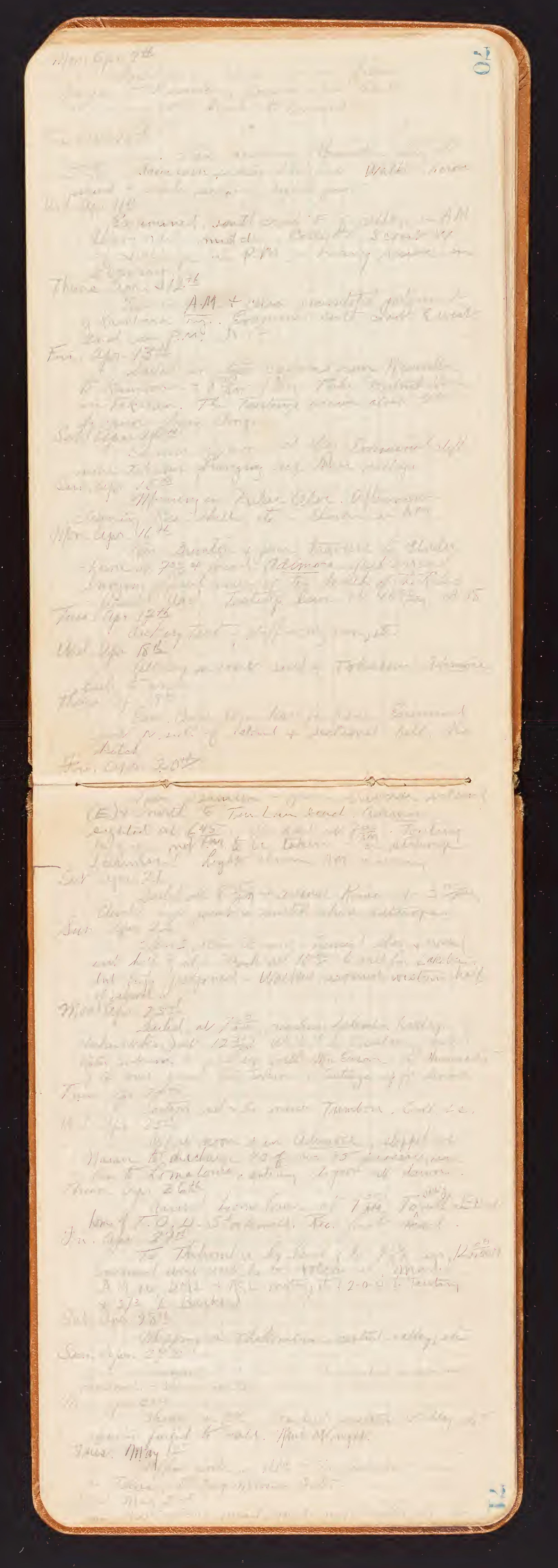




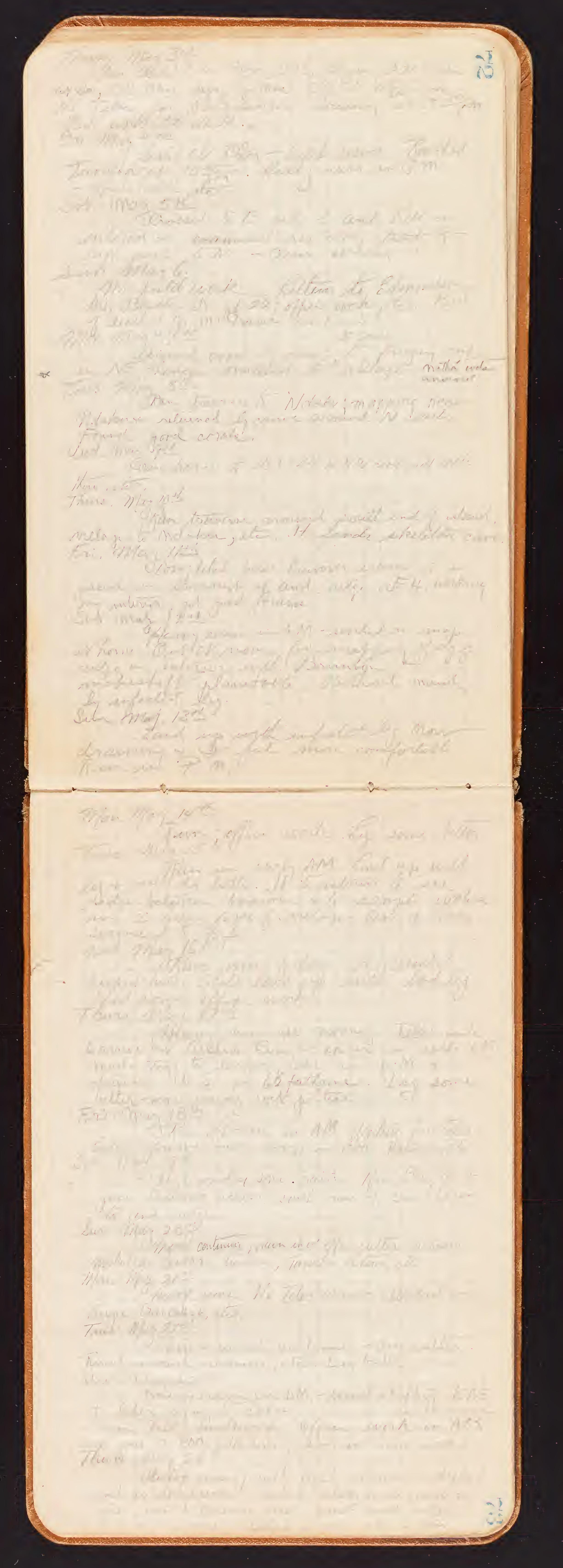




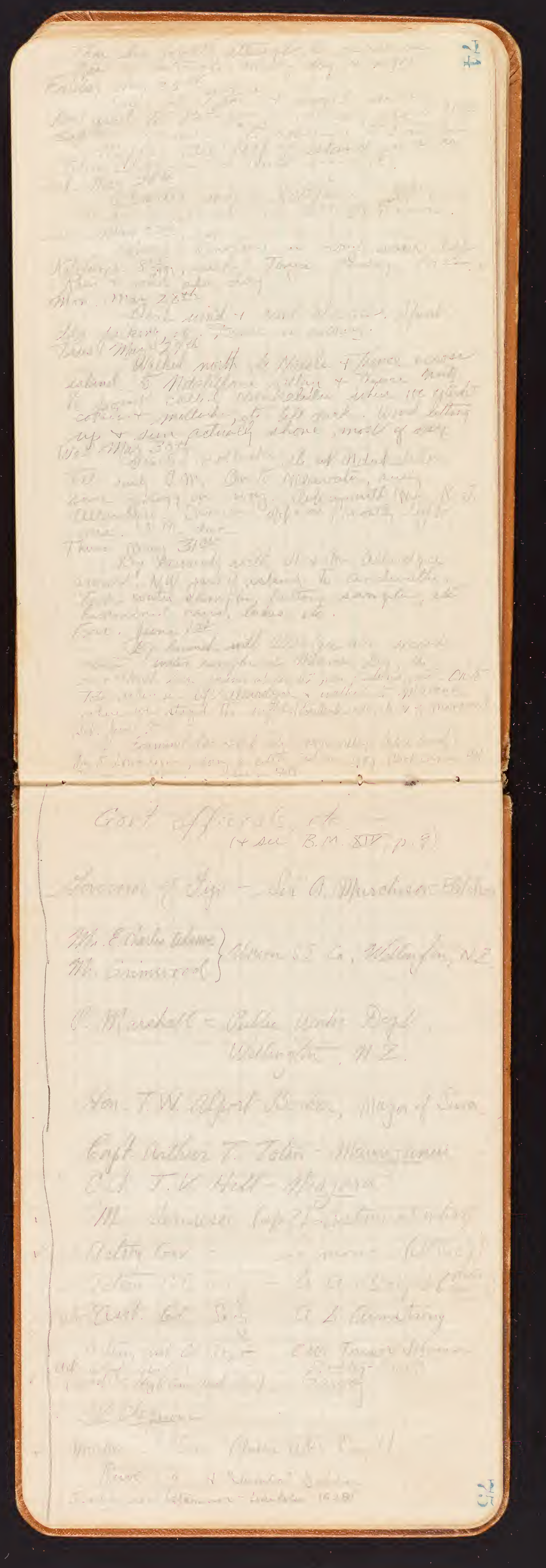




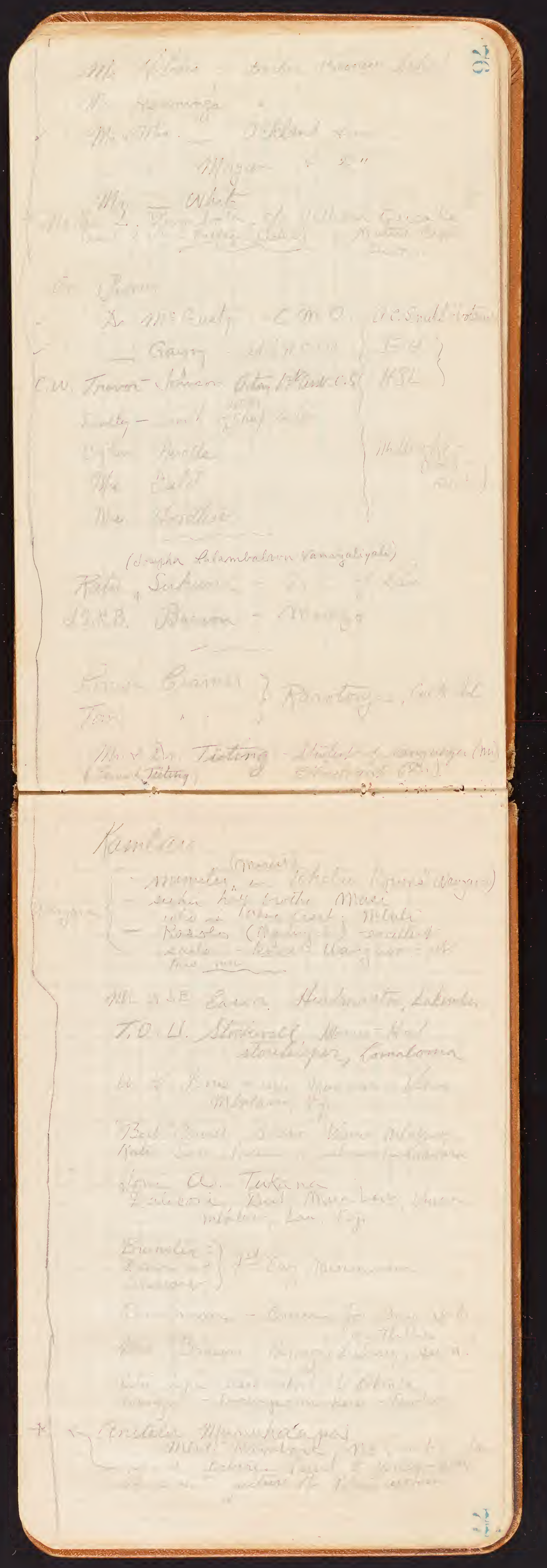




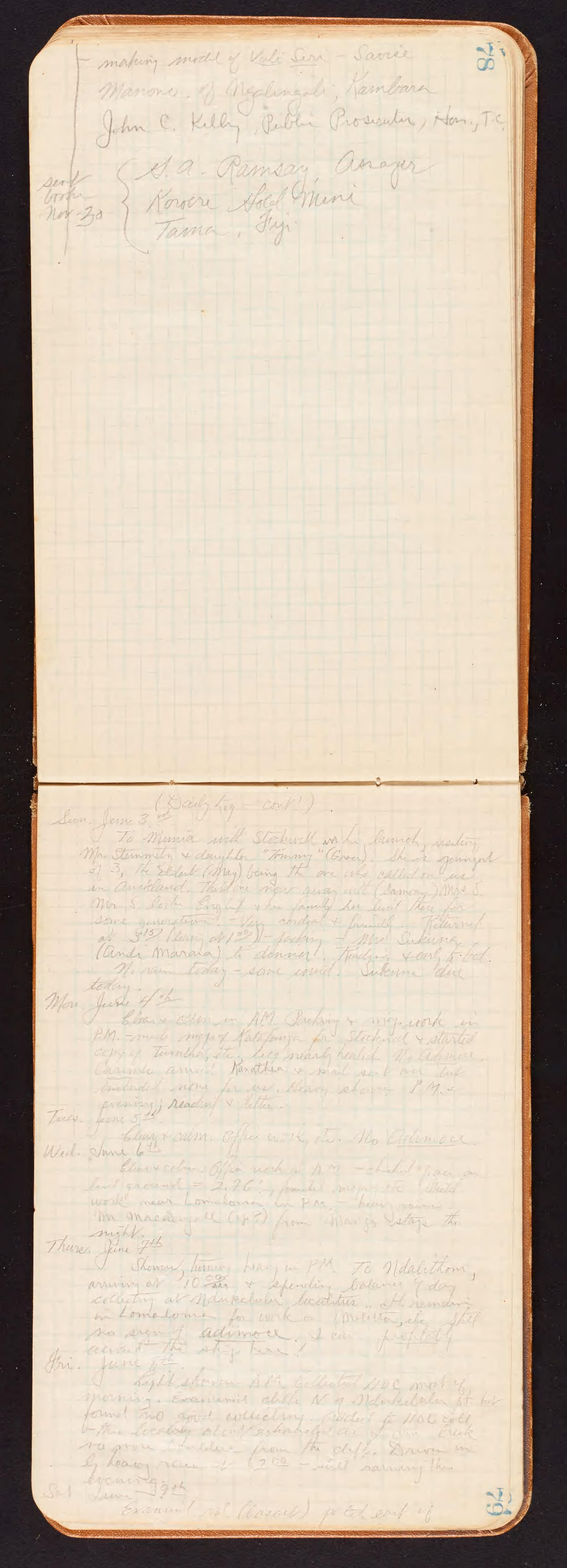




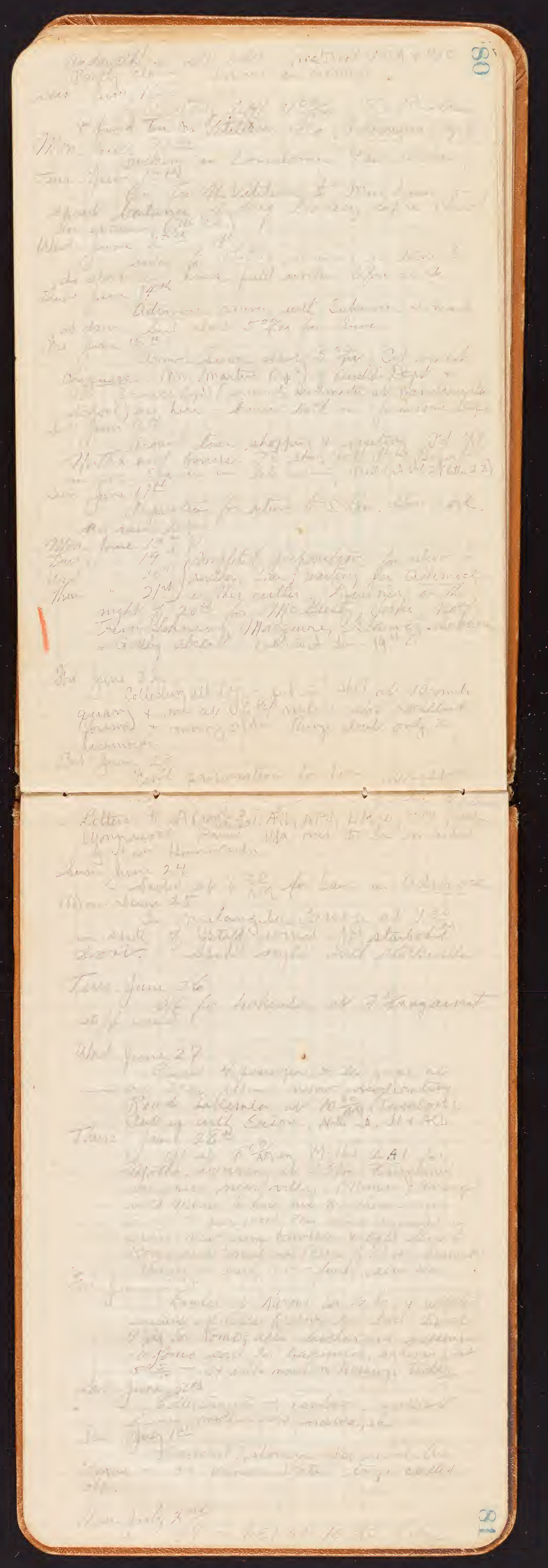




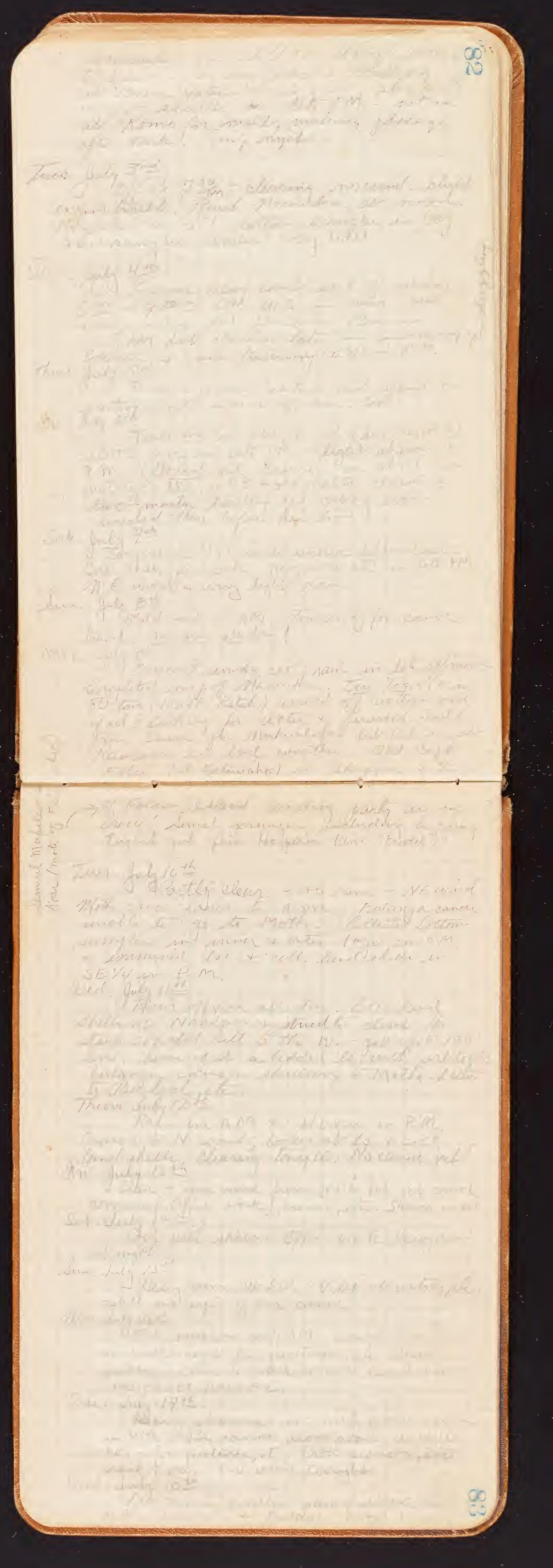




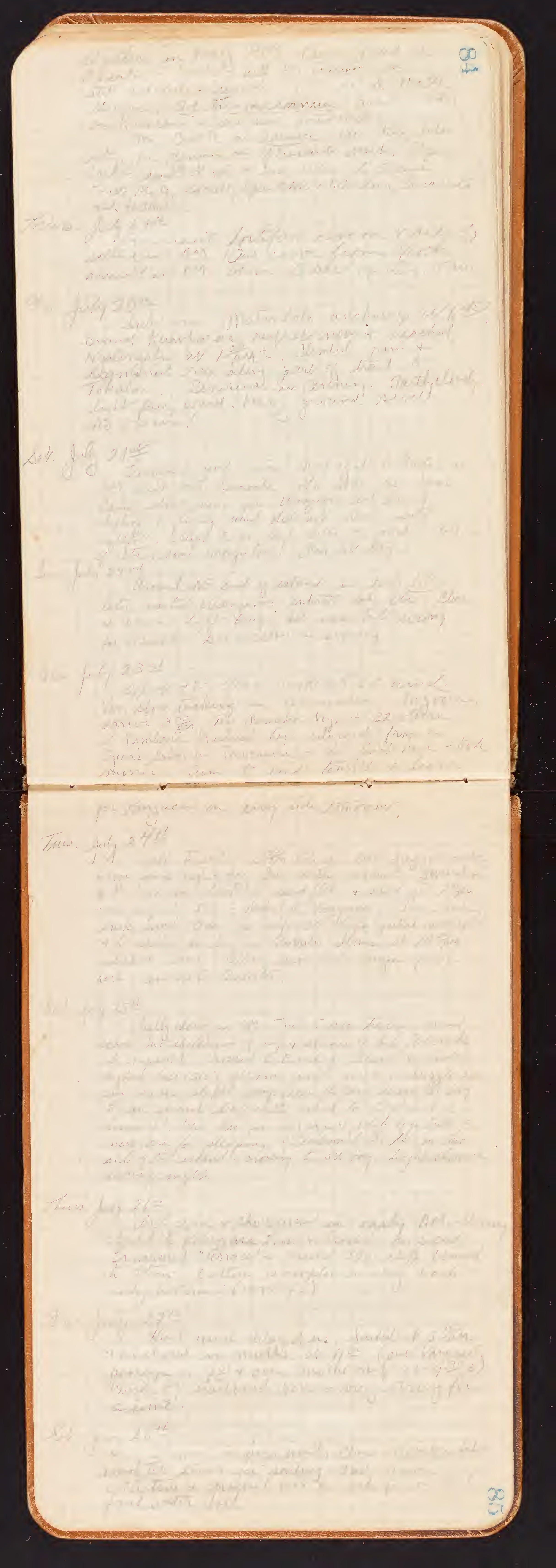




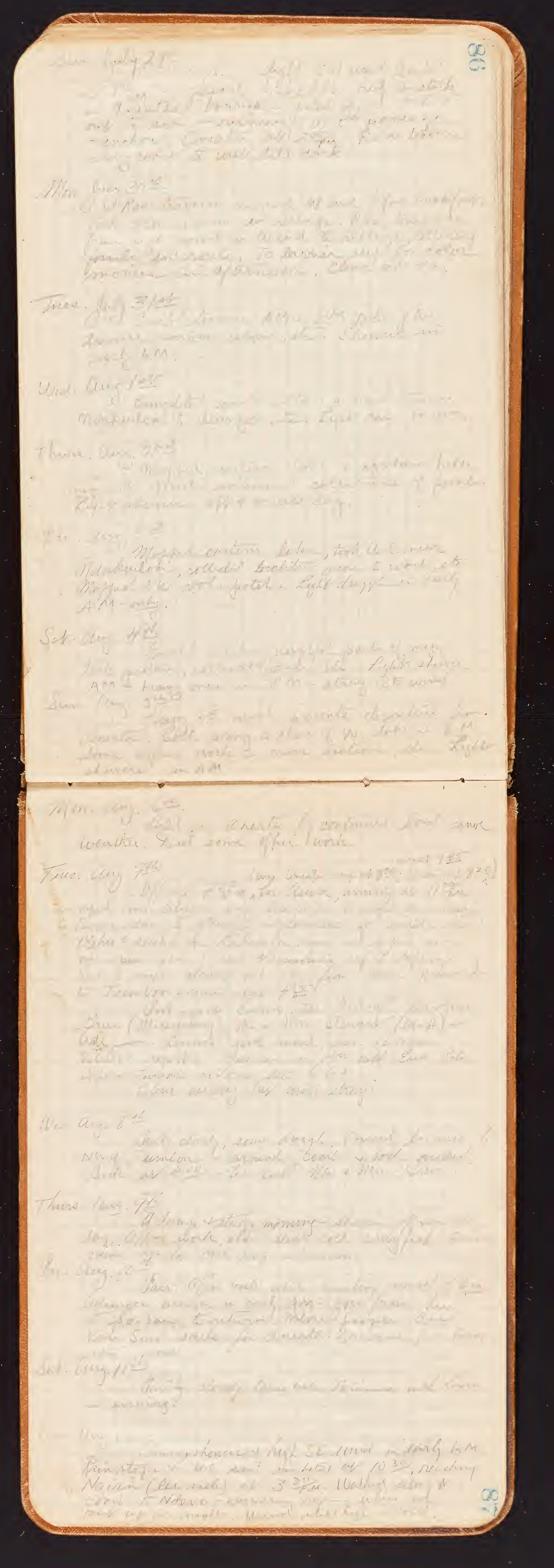




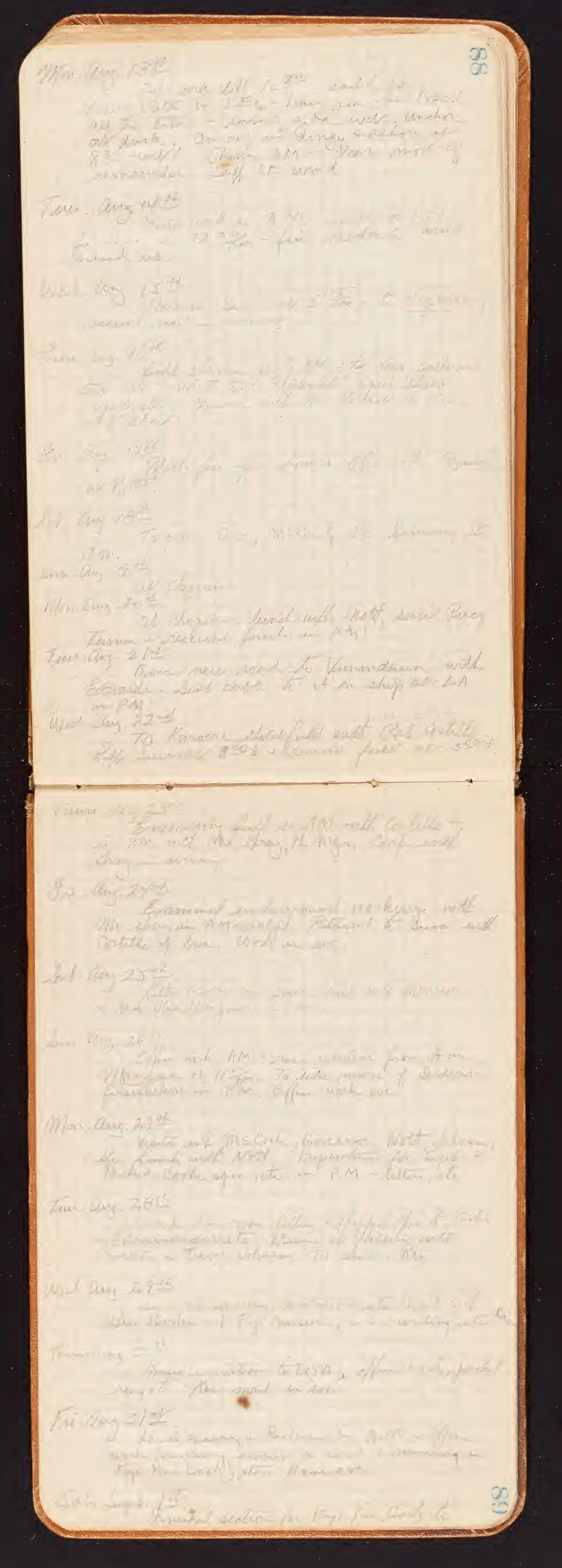




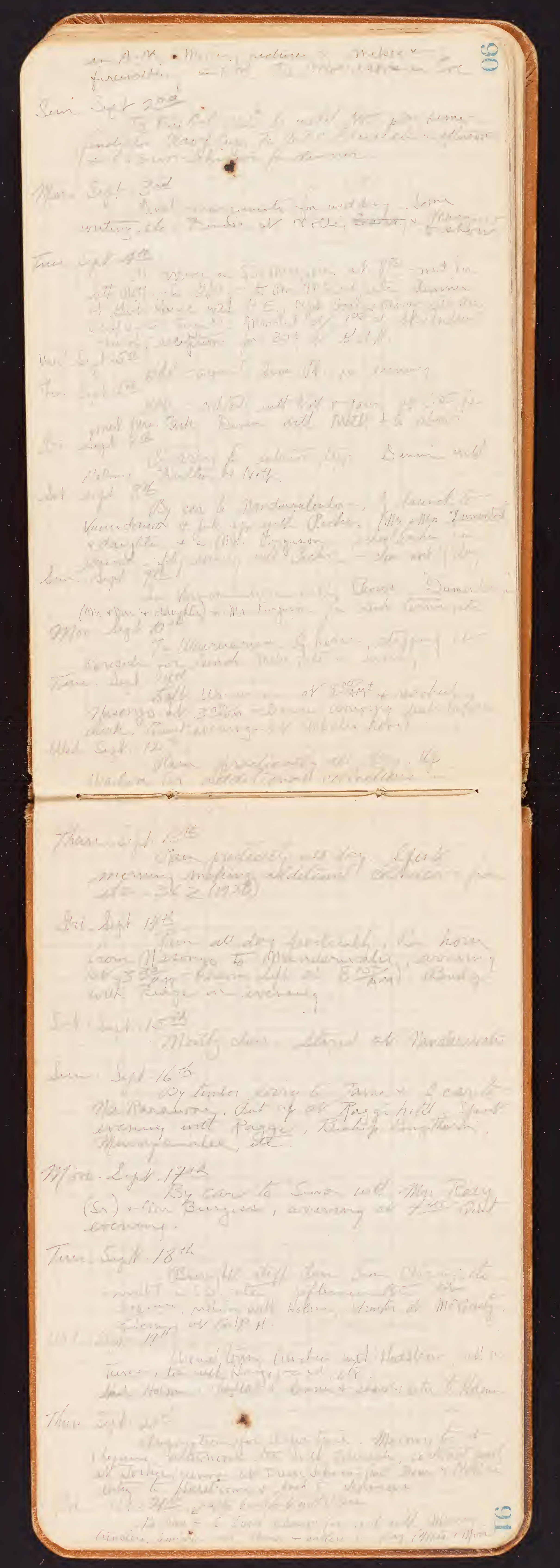




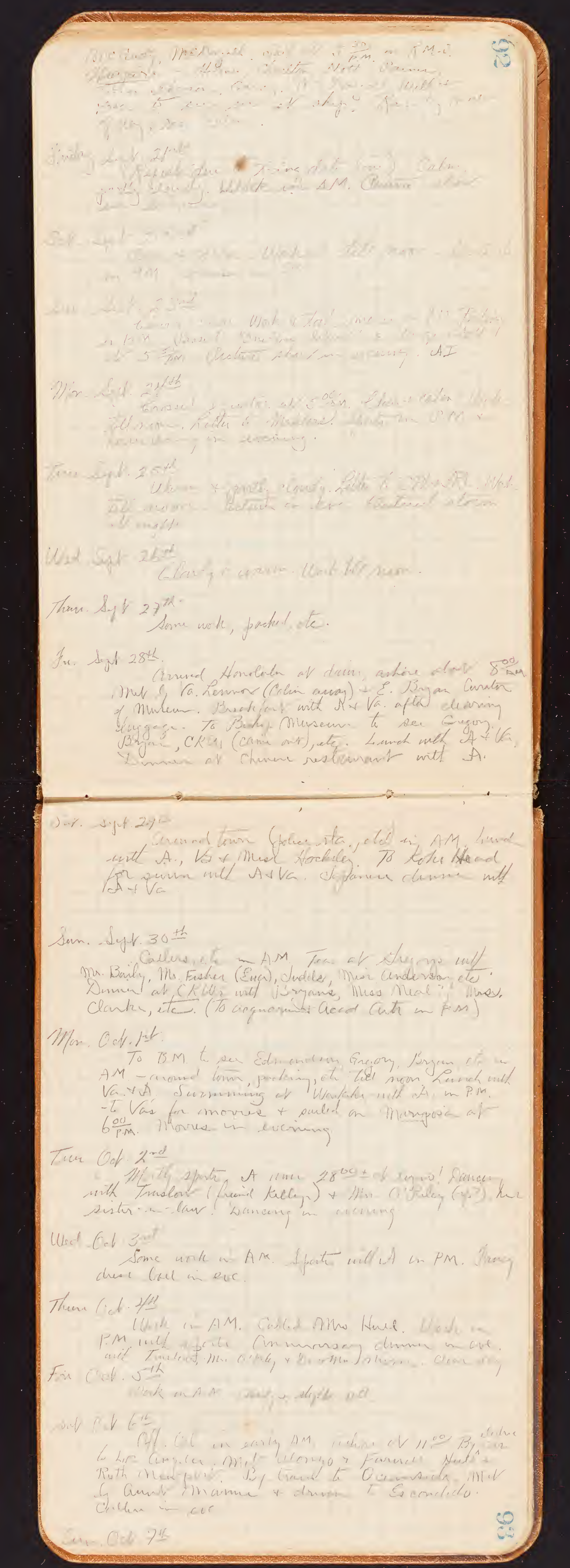




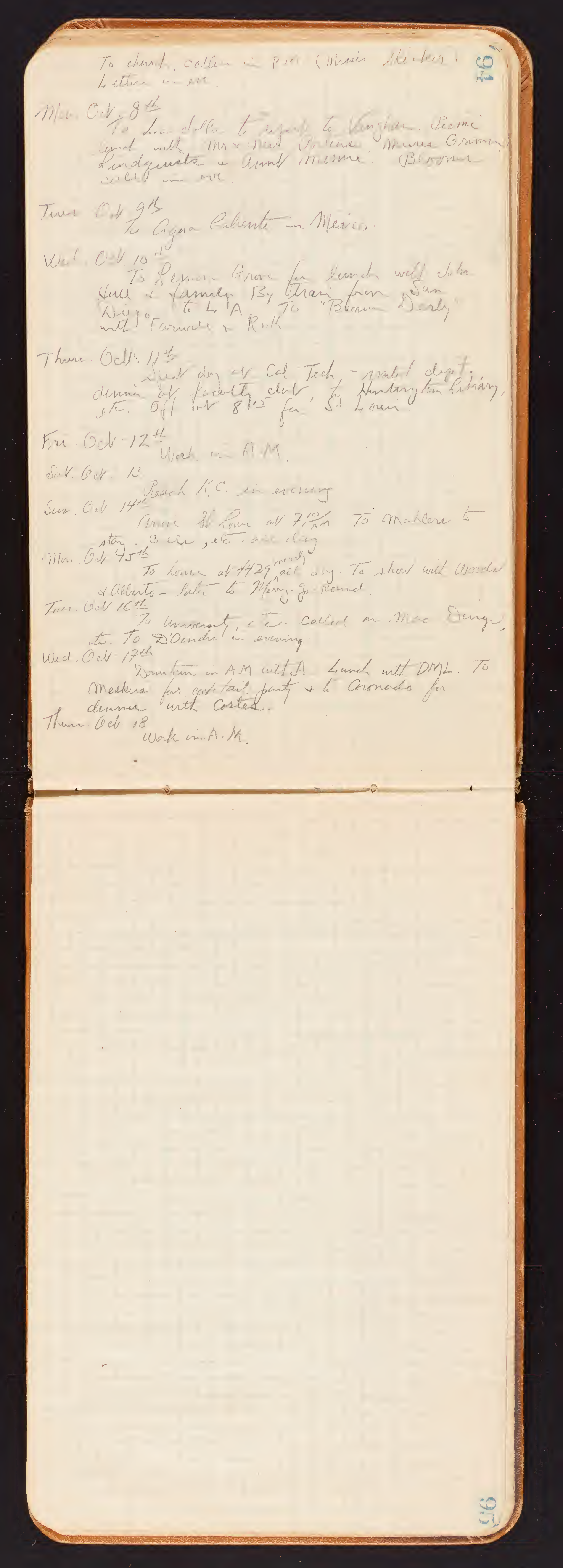




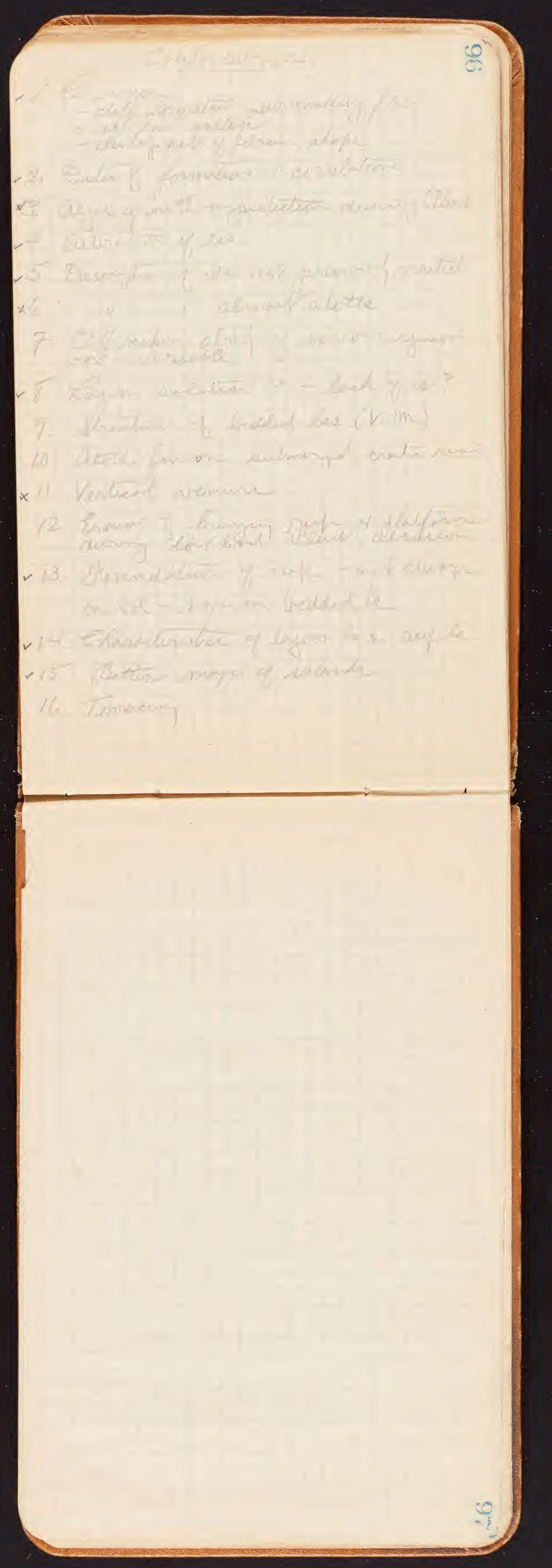




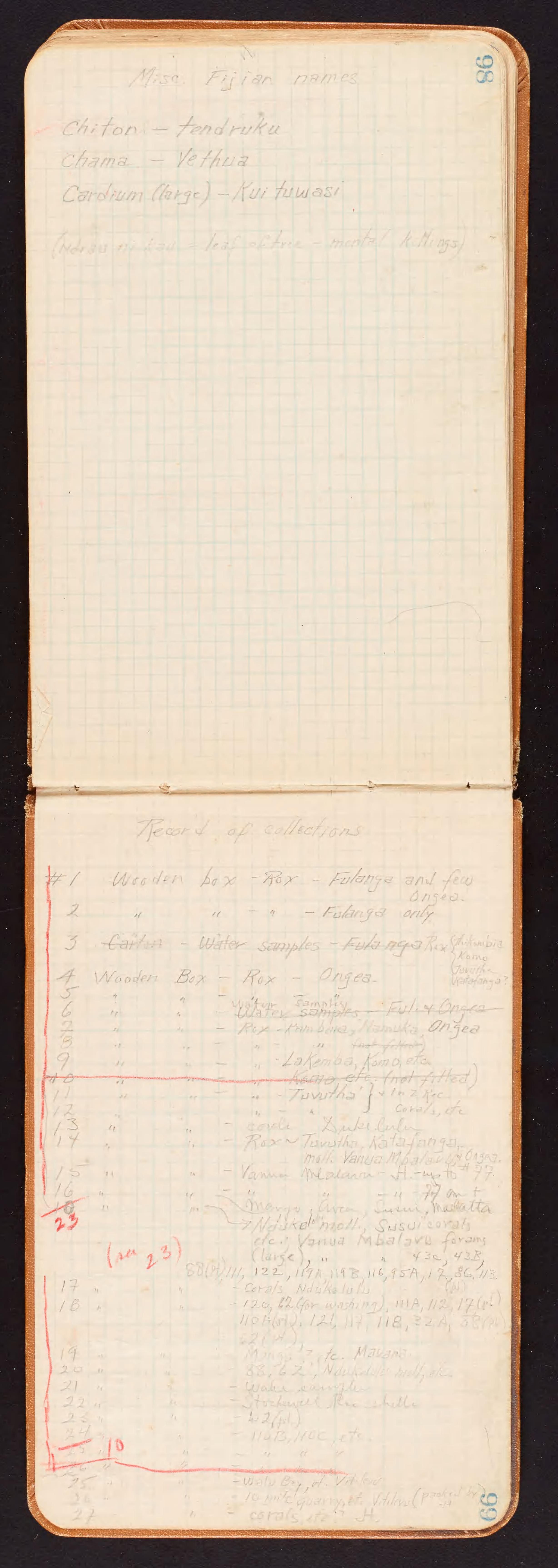




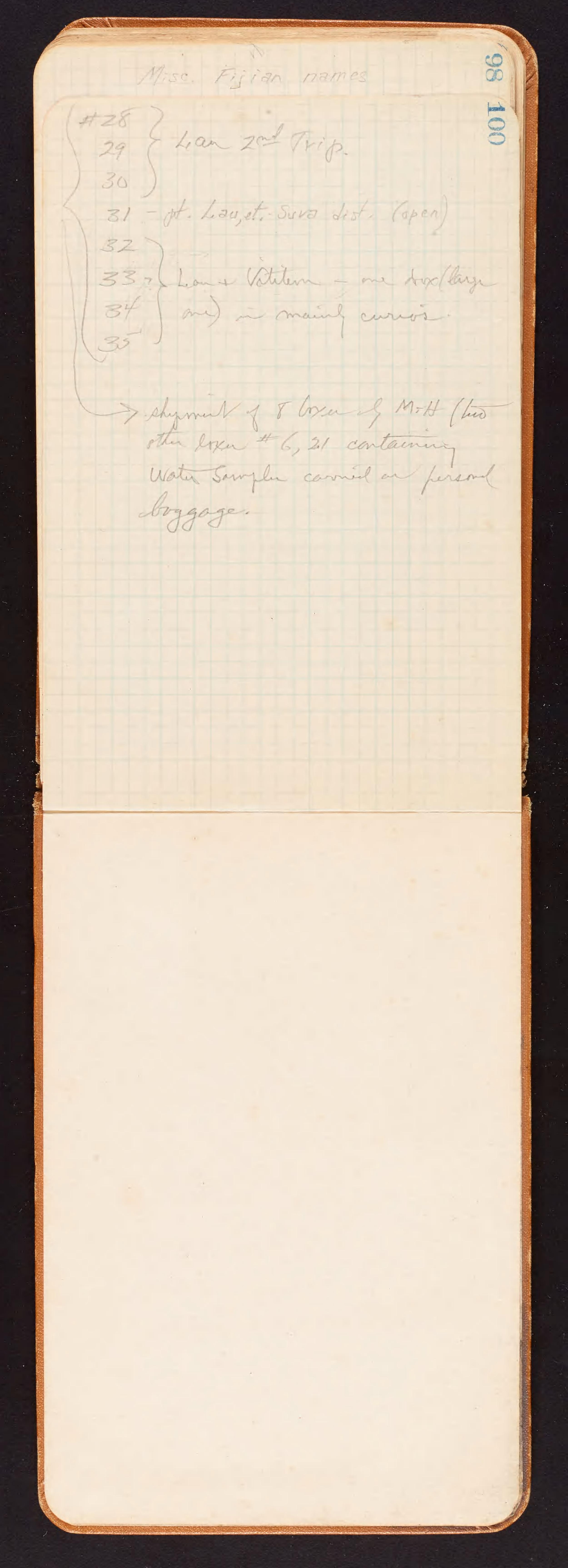




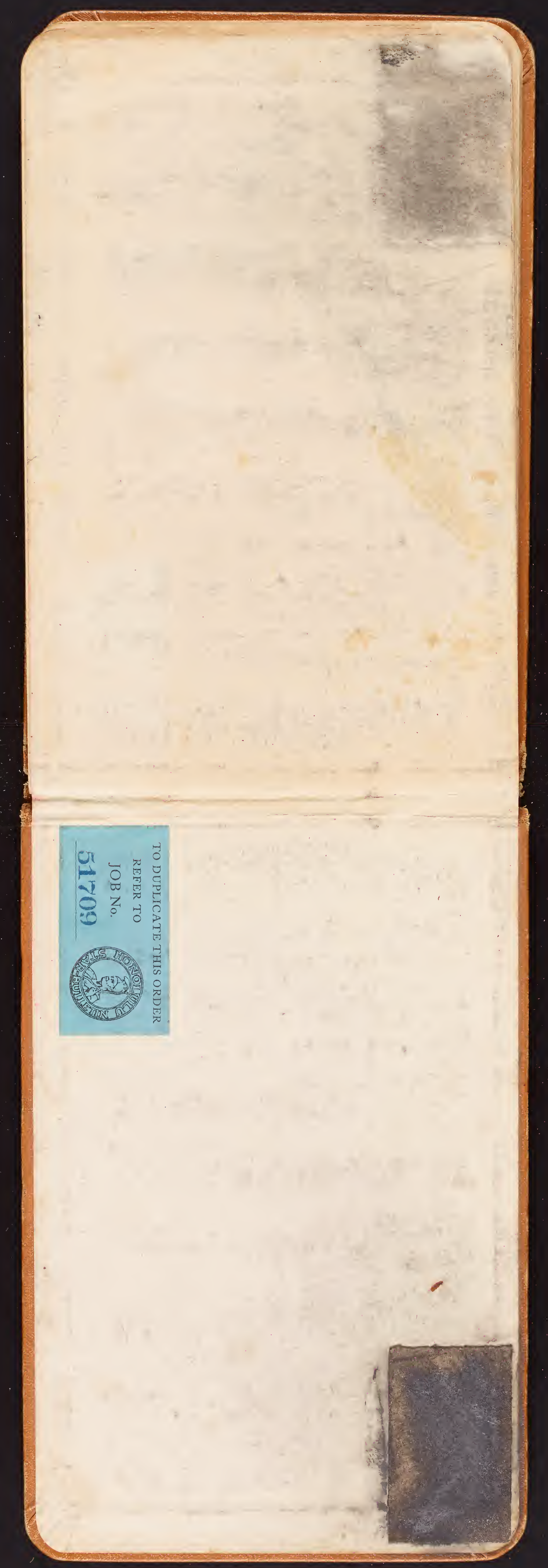




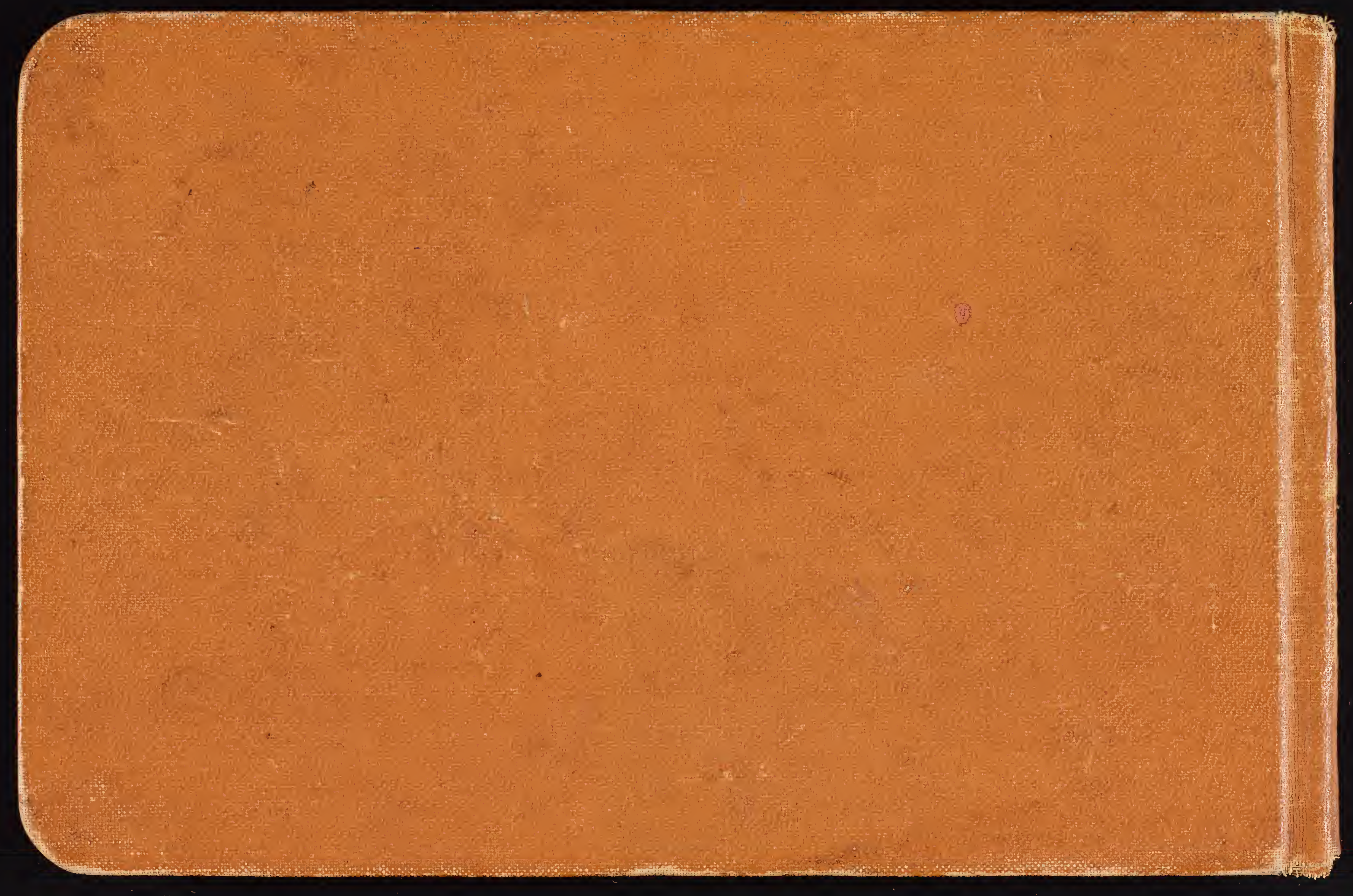

